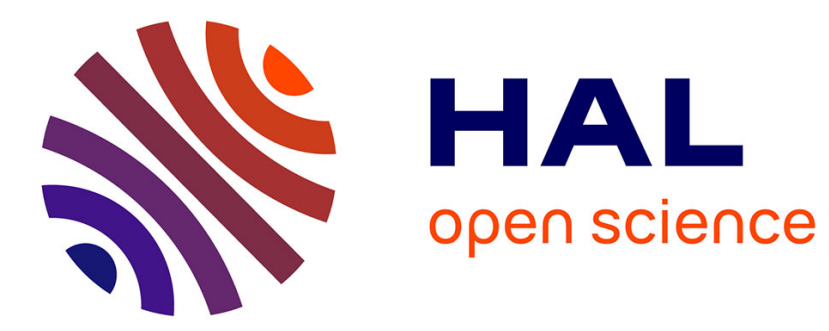

\title{
Kinematic amplification strategies in plants and engineering
}

Victor Charpentier, Philippe Hannequart, Sigrid Adriaenssens, Olivier Baverel, Emmanuel Viglino, Sasha Eisenman

\section{- To cite this version:}

Victor Charpentier, Philippe Hannequart, Sigrid Adriaenssens, Olivier Baverel, Emmanuel Viglino, et al.. Kinematic amplification strategies in plants and engineering. Smart Materials and Structures, 2017, 26 (6), pp.63002 - 63002. 10.1088/1361-665X/aa640f . hal-01618277

\section{HAL Id: hal-01618277 \\ https: / hal-enpc.archives-ouvertes.fr/hal-01618277}

Submitted on 17 Oct 2017

HAL is a multi-disciplinary open access archive for the deposit and dissemination of scientific research documents, whether they are published or not. The documents may come from teaching and research institutions in France or abroad, or from public or private research centers.
L'archive ouverte pluridisciplinaire HAL, est destinée au dépôt et à la diffusion de documents scientifiques de niveau recherche, publiés ou non, émanant des établissements d'enseignement et de recherche français ou étrangers, des laboratoires publics ou privés. 


\title{
Kinematic amplification strategies in plants and engineering
}

Victor Charpentier*1, Philippe Hannequart*2,3, Sigrid Adriaenssens ${ }^{1}$, Olivier Baverel $^{2}$, Emmanuel Viglino ${ }^{3}$, Sasha Eisenman ${ }^{4}$

${ }^{1}$ Department of Civil and Environmental Engineering, Princeton University, Princeton, NJ, USA

${ }^{2}$ Laboratoire Navier, UMR 8205, École des Ponts, IFSTTAR, CNRS, UPE, Champs-sur-Marne, France

${ }^{3}$ Arcora, Ingérop Group, Rueil-Malmaison, France

${ }^{4}$ Department of Landscape Architecture and Horticulture, Temple University, Ambler, PA, USA

*The authors designated have contributed equally to the research and writing of the manuscript

\begin{abstract}
:
While plants are primarily sessile at the organismal level, they do exhibit a vast array of movements at the organ or sub-organ level. These movements can occur for reasons as diverse as seed dispersal, nutrition, protection or pollination. Their advanced mechanisms generate a myriad of movement typologies, many of which are not fully understood. In recent years, there has been a renewal of interest in understanding the mechanical behavior of plants from an engineering perspective, with an interest in developing novel applications by up-sizing these mechanisms from the micro- to the macro-scale. This literature review identifies the main strategies used by plants to create and amplify movements and anatomize the most recent mechanical understanding of compliant engineering mechanics. The paper ultimately demonstrates that plant movements, rooted in compliance and multi-functionality, can effectively inspire better kinematic/adaptive structures and materials. In plants, the actuators and the deployment structures are fused into a single system. The understanding of those natural movements therefore starts with an exploration of mechanisms at the origins of movements. Plant movements, whether slow or fast, active or passive, reversible or irreversible, are presented and detailed for their mechanical significance. With a focus on displacement amplification, the most recent promising strategies for actuation and adaptive systems are examined with respect to the mechanical principles of shape morphing plant tissues.
\end{abstract}




\section{Introduction}

Biology serves as inspiration for engineering kinematics and has been doing so for a long time. Designers tend to search nature for solutions to particular engineering problems. This direct approach has provided many successful engineering products but has constrained us, engineers, to the role of observers. As exposed by Vincent [1], the solutions provided by biology to problems challenge our rational, rigorous problem solving approaches. Taking note of the variety of mechanisms involved in plant movements, there has been a renewal of the interest in understanding the mechanical behavior of plants for structural morphings. Structural morphings modify the structures with continuous shape changes only, no movements of discrete parts are involved [2]. As such they are a subcategory of adaptive structures, a structure is called adaptive as soon as it presents an alteration of its geometry and/or material properties [3]. Plants are morphing structures in the purest sense of the term. The continuity of the material is key to the existence of a living entity and to the coherent movement of autonomous structures. The diversity of environments and situations where plants successfully adapted provides a breadth of problem solving examples. There is however a need to break down the mechanical strategies developed in plants to insure that identified kinematic mechanisms are made available to the designer.

Engineered adaptive structures and actuators increasingly implement compliance in their design. As such, the observation of plant-generated movements can lead to novel morphing schemes in engineered structures. The origins of active plant movements and plant mechanics have been presented in detail in [4-12]. In light of material advances, downscaling of manufacturing and computer aided design, many new interdisciplinary applications appear that make use of a nature-inspired palette of solutions for engineering problems. In engineering the interest for morphing is growing in many fields such as aerospace industry [2, 13], building engineering [14], micro-scale actuation [15], wind turbines [16, 17], automotive industry [18] or medicine [19].

Kinematic amplification in plants and in engineering is reviewed in this paper. The kinematic amplification, also called distance advantage, is defined as the ratio of output displacement to input displacements in a kinematic system. The amplification ratio measures the efficiency of structures at transforming the input actuation into large displacements. The input displacement considered in this paper encompasses both the rigid bar displacements of classical mechanisms and the displacement resulting from material strain over the whole length of the active material. Assessing the kinematic amplification in mechanisms is essential to understanding and emulating their strategies in adaptive structures. Parallel to kinematic amplification but not treated here is force amplification, also referred to as mechanical advantage. It is the ratio of the output force over the input force of the mechanism. Force amplification is not considered in this review but it is not completely unrelated to kinematic amplification. In the simpler case of lever mechanisms or gears, the force amplification ratio (FAR) is the inverse of the kinematic amplification ratio (KAR) ${ }^{1}$.

The hypothesis guiding the biology study is that even the most basic generations of plant movement involve some degree of kinematic amplification. In hydraulics powered movements (active or passive), the input displacement considered for the kinematic amplification is the total expansion of the active layer of tissue (intermediate-scale assemblage of cells to create a rigid building material). Such mechanism can be so effective that the kinematic amplification ratio can reach $\sim 200$ in Aldrovanda Vesiculosa [20] and $\sim 160$ in pine cones [21]. Similarly high KAR values have been measured in bimetal actuators ( $\sim 140$ in [22]), which gives ground for a comparison of plant and engineering mechanisms. In animals this value is often lower due to the lever mechanisms in musculoskeletal systems. For instance, the KAR reaches values of $\sim 2$ in the mantis shrimp raptorial appendage [23] or $\sim 6$ in the human biceps-elbow joint [24].

This review presents an organized comparison of natural and state-of-the-art engineered movements and draws parallels to nature from recent engineering studies to categorize strategies that have successfully replicated or synthesized plants. Plant mechanics have often been described on a case-by-case basis. By

\footnotetext{
${ }^{1}$ Considering a lever of short arm length $a$ and long arm length $b$, the FAR given by the equation of equilibrium at the fulcrum is $a / b$ while the KAR given by the ratio of arc length of the end points of the lever is $b / a$.

Considering a set of two gears A (input) and B (output) of respectively radii $r_{A} \& r_{B}$ and angular speeds $\omega_{A} \& \omega_{B}$, the FAR given by the gear reduction is $r_{B} / r_{A}$. while the KAR given by the equation of equal speed at the point of contact is $r_{A} / r_{B}$
} 
grouping the kinematic amplification types in plants, the objective is to provide the designer a toolbox to explore new possibilities in compliant mechanisms. By placing those amplification mechanisms in their context, another objective is to help the engineer understand the origin of the solutions found in biology and to create the basis for new innovative combinations of actuations and amplifications. The engineered structures are not necessarily directly inspired by plant mechanics but similarities organically appeared between the two. Therefore the review also includes a large exploration of engineering kinematic amplification mechanisms.

In section 2 the origins of plant movements and five identified kinematic amplification mechanisms are presented, before switching to a comprehensive assessment of movement generation and amplification in the most recent technology developments in section 3. The essence of the mechanical principles in plants and in built actuators presented in the document is synthesized in section 4 . 


\section{Kinematic amplification in plant structures}

\section{$2.1 \quad$ Foreword on cellular material and plant actuation}

Plant cellular structures can be regarded as hierarchical, living material and as such they differ from man-made materials. In order to understand kinematic amplification mechanisms, an introduction to the characteristics of this material provides grounds for comparison between natural and engineered materials and actuations.

\subsubsection{Cell structure and resulting material properties}

Unlike the cells of animals, plant cells are surrounded by a stiff cell wall comprised of a composite material with organized cellulose fibers ingrained in a pectin matrix $[25,26]$. Due in part to the stiffness of the walls, growth and movement of plants are generated by the variation of a large internal hydrostatic pressure inside the cells called turgor pressure [27]. The orientation of the cellulose fibers largely determines the overall shape and behavior of the plant cells and tissues. The degree of alignment of cellulose micro-fibrils is correlated to the degree of anisotropic expansion of the cell under an increase of turgor pressure [26, 28]. In addition, the angle of the aligned fibers with the cell axis determines the magnitude of the anisotropic deformation [29]. At the material level, this anisotropic behavior is caused by the global alignment of the fibers in the cell walls (see Figure 1) [30, 31]. The directionality of the material properties plays a role in both irreversible (e.g. growth motions) and reversible (e.g. turgor induced) motions of plants.
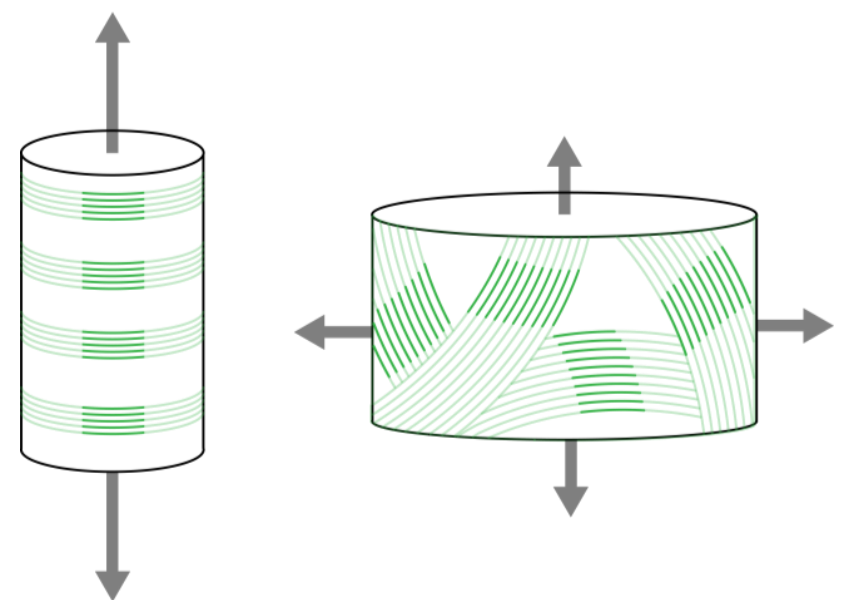

Figure 1 Microfibrillar arrangement influencing the growth of plant cells - with parallel, horizontal microfibrillar orientation the cell grows longitudinally (left); with randomized orientations the growth becomes isotropic (right)

The mechanical properties of the tissue result from cell characteristics such as wall thickness, cell geometry and turgor pressure magnitude [32,33]. Plant materials exhibit elasto-plastic behavior with a plastic strain limit around $2 \%[34,35]$. Reversible, turgor-based motions involve the elastic regime of the cell walls while irreversible motions of growth require elongation of the cells and therefore involve the plastic regime [36]. The elastic modulus of extensible and reversible specialized cell walls varies between orders of magnitude of $100 \mathrm{MPa}[37]$ and $1 \mathrm{GPa}[34,38]$ while it is much higher in cells found in woods, usually between 15 to $25 \mathrm{GPa}$ for the hardest woods $[39,40]$. Interestingly, the turgor pressure has a direct influence on the stiffness of the material: in parenchyma cells (cells with thin, nonspecialized cell walls) a linear correlation has been reported between the turgor pressure and the elastic modulus of tissues [12, 41]. However, this correlation appears only when large strains occur [42]. Comparing a sample of carrot material with internal cellular pressure preserved (fresh tissue) to a sample without internal pressure (cooked for $1 \mathrm{~min}$ ), Warner et al. [33] underline that relationship with qualitative measurements of differing elastic moduli in large strains. Studies of fluid filled cellular material highlight the need for nonlinear elastic modulus models to capture the behavior of the plant material $[29,33,42]$. 
Figure 2 Schematic variation of cell volume in the tissue due to water transport - Vtop and Vbot represent the volume of the top and bottom cells respectively - $L$ is the length of the sample and $\Delta L$ is its variation.

\subsubsection{Material hierarchy}

Plant tissues are complex materials that implement an organization of multiple hierarchical structural levels. The construction of these natural materials operate at scales ranging from $10^{2} \mathrm{~m}$ in tree trunks [46] to $10^{-7} \mathrm{~m}$ in cell walls [9]. Between these two extreme values, it is possible to distinguish between five to twelve structural levels [47]. In the case of the structure of wood stems, this hierarchal material organization translates into seven levels: tissue, cell, laminated cell walls, individual walls, cellulose fibers, microfibrils and protofibrils [48]. This organization is found in many biological materials such as bones [49], tendons [50] or hexactinellid (glass) sponges [51]. In essence this organization allows the construction of very large structures based on a limited number of building blocks. It also creates the possibility of introducing combinatory variability at each level of the hierarchy. The hierarchical organization is adapted for each situation through the optimization of the arrangement of each structural level, and allow for material repair mechanisms by relying on lower levels of material hierarchy [52, $53]$.

\subsection{Amplification of actuation in plant kinematic mechanisms}

Plant kinematic structures are actuated by hydraulics, passive or active, but also by external forces, such as the visit of a pollinator. However a number of those actuation sources provide only small magnitudes of displacements. To answer the need of large displacement, plants have evolved efficient kinematic amplification mechanisms to increase the magnitude of the actuation. In this section, the amplification mechanisms in plants are reviewed and analyzed based on mechanical principles. 
2.2.1 Bilayer action through the shrinking and swelling of cells

The mechanical basis of this kinematic amplification strategy is the strain continuity imposed to rigid bodies under differential tissue expansion (in active or passive hydraulics). The compatibility condition in solids implies that strains are continuous [54]. Therefore the difference of swelling/shrinking magnitude between layers creates large deformations of the structure via bending, to accommodate strains within the material [6]. The input displacement in this kinematic amplification is the total expansion of the expanding layer, while the output displacement is the resulting bending. This section focuses on planar bendings created in pulvini.

\subsubsection{Omnidirectional movements from pressure differentials in pulvini}

Many heliotropic (solar tracking) plants such as Phaseolus vulgaris (regular string beans) or Ranunculus adoneus implement reversible tracking movements [55-57]. Heliotropic movements are dynamic, directional and involve short diurnal cycling as opposed to general irreversible phototropic movements associated with growth [58]. The pulvinus is an appealing structure for plant biomimetic endeavors. The pulvinus is a cylindrical motor organ in its most general form. It has a length of a few millimeters and is usually located at the base of the petiole (stalk attaching the leaf blade to the stem) [59]. In pulvini presenting omni-directional movement, motor cells radially surround a rigid core (Figure 3A) made of thicker-walled, parenchyma cells $[60,61]$. At the rest position, the motor cells all have the same volume around the core. When the pulvinus is activated for a certain orientation $(\beta)$, the cells at an angle opposite to the desired deformation direction swell and the pulvinus bends in-plane to perform the movement. The magnitude of the swelling determines the bending angle $(\theta)$. With this hydraulic bending, plants can follow the elevation and the azimuth of the sun throughout the day with a precision of up to $5-6^{\circ}[59$, 62].

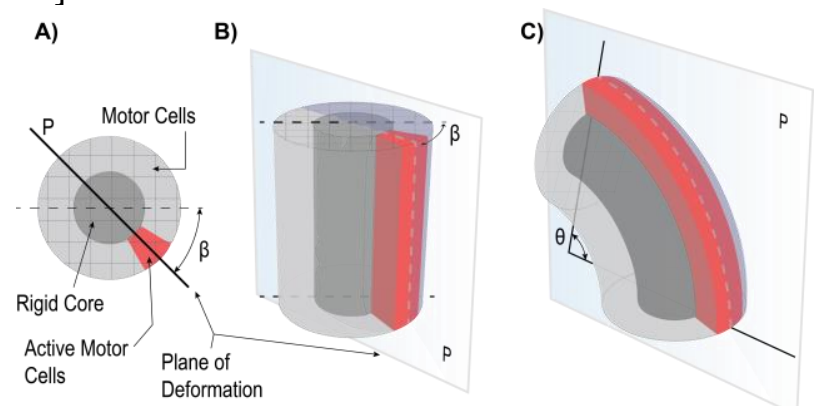

Figure 3 (A) Cross section of omnidirectional pulvinus [61] with active cells at azimuth angle $\beta$ - (B) Plane of deformation $\mathbf{P}-(\mathbf{C})$ In-plane deformation of the pulvinus and elevation angle $\theta$

In simpler mechanisms, the pulvini present more limited planar movements [63, 64]. In this case, the structure of the pulvinus is similar to the omni-directional system but the distribution of motor cells is limited to the plane of the movement. In this plane, the motor cells are located on both sides of the rigid core. Such are the leaves of the Albizzia julibrissin that consistently fold at night but do not implement multidirectional solar tracking during the day [63]. This type of amplification carries strong similitudes with bilayer thermostats and pneumatic actuation, which are presented in Section 3 of this paper.

\subsubsection{Versatility and adaptability of the bilayer effect in Mimosa pudica}

In addition to diurnal folding due to variations of light intensity, Mimosa pudica exhibits defensive folding motions following touch or vibration stimuli. These movement are triggered by rapid changes of temperature, electric stimulation and wounding [65, 66]. This non directional (thigmonastic) movement triggered by touch or vibration is relatively fast compared to other plants [67]. However $M$. pudica does not implement elastic instabilities to increase the speed of the folding movement (duration around 1s [68]). The movement is solely generated by swelling and shrinking and amplified by a bilayer effect. Four structural levels can be identified in the structure of $M$. pudica (see Figure 4) (1) the principal structure is the stem, (2) petioles are attached to the stem, (3) pinnae (usually two pairs, carrying the leaflets) are connected to each petiole, and finally (4) each pinna has 10-20 pinnules (leaflets) attached directly by their base to the pinna $[69,70]$. Structures (2), (3) and (4) compose a leaf. Three levels of movements are observed in $M$. pudica. They are generated by three pulvini, each is located at the junction of two previously mentioned structural entities [65]. 


\section{DAY}

Non-stimulated

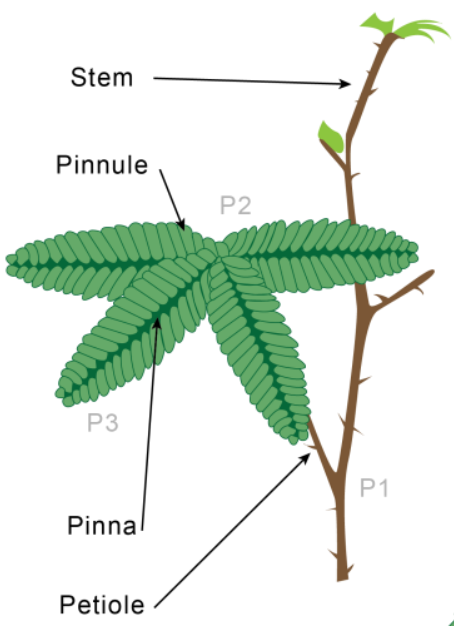

P\# - Pulvinus Activated

P\# - Pulvinus Not Activated
DAY

Stimulated

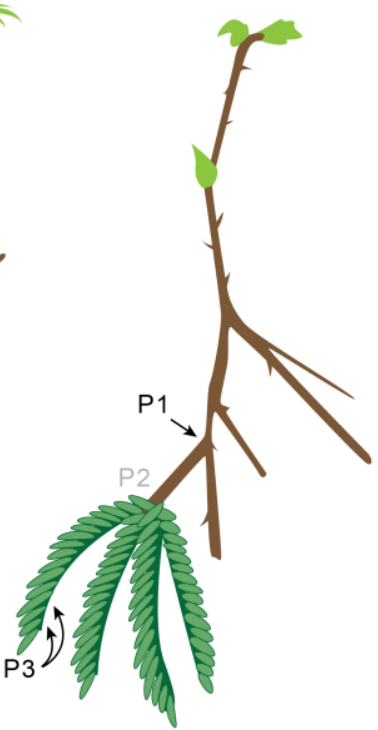

NIGHT

Non-stimulated

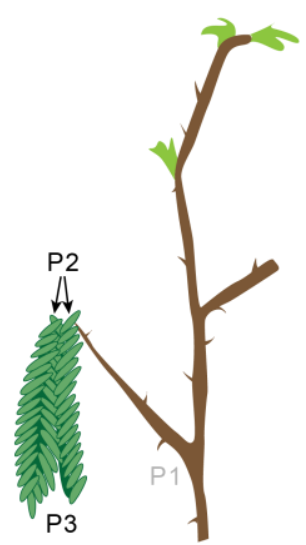

NIGHT

Stimulated

Figure 4 Touch stimulated movements during day and at night for the three pulvinus levels of Mimosa pudica - P\# denotes the following pulvini - P1 or primary: between the stem and the petioles, P2 or secondary: between the petioles and the pinnae and $P 3$ or tertiary: between the pinna and the pinnules - The activated pulvini are written in darker font.

The movements of $M$. pudica are not only triggered by touch but also follow the diurnal cycles with the pulvini folding in absence of light [65]. Touch related movements involve the primary and tertiary pulvini while the sleep movements involve all the pulvini [71]. The three types of pulvini allow two different typologies of planar deformation: upward or downward. The primary and secondary pulvini deform downward while tertiary pulvini deform upward $[65,66,71]$. This planarity has been confirmed for the tertiary pulvinus by observation of the cellular layout. The unidirectional orientation of the motor cells in the plane of the movement in both layers of the tertiary pulvinus confirms that only unidirectional movement is possible [65]. In the case of the primary pulvinus however, recent evidence suggests that its cellular structure is similar to an omnidirectional pulvinus with a xylem (central fluid transport core) allowing bending in all directions [68]. In case of stimulation by light (generating slower movement than touch), both horizontal and vertical movements of the primary pulvinus are reported [68]. When only planar displacements of the primary pulvinus are considered, the observation of the cellular displacement in the upper and lower sections confirms that the upper cells are expanding and the lower cells are contracting [68].

M. pudica is part of the Fabaceae (or Leguminosae), which contains a number of other species that implement similar pulvinus-generated movements. Among them are Samanea saman [72], Paraserianthes lophantha [73], Albizzia julibrissin [63], Phaseolus vulgaris [64] and Codariocalyx motorius [74]. The pulvinus is a very polyvalent actuator allowing either two or one rotational degrees of freedom.

\subsubsection{Amplification by geometry and material anisotropy in passive movements}

Flowering plants develop fruits to aid in seed dispersal. During their development those structures are connected to the vascular system of the plant. However after maturation and separation from the vascular system, most seeds and many fruits become autonomous structures. Similarly, pollen grains also act autonomously once released. The focus of this section is on autonomous structure and their kinematic mechanisms created from hydration. The external actuation imposes the actuation cadence of the autonomous structure. Relying on a regular external actuation is therefore key to carrying out the function of the structure. Interestingly, the highly-regular diurnal variation of air humidity [75] is used as a reliable actuator for many seed cells rehydration. Hygroscopic plant tissues shrink and swell largely 
as a function of variations in air humidity [6]. The majority of reacting cells in seed tissues are dead dry cells. In general seeds contain between 5 and $15 \%$ of water [27] and therefore present great potential for rehydration.

\subsubsection{Folding of shells}

Shells are 3D continuous structures presenting one dimension considerably smaller (thickness) than the other two (width and length). Shells can be flexible or stiff depending on their boundary conditions. In the case of autonomous structures, pollen grains $[76,77]$ or seedpods $[78,79]$ provide valuable examples of flexibility.

Pollen grains are structures carrying genetic information for reproduction. The grains present an outer surface divided in two surface types: one or several apertures (straight zones on surface in Figure 5A) constituted of hydrophilic material and impermeable surfaces for the rest of the grain [80]. After being released pollen grains desiccate. The rate is variable but can reach $20 \%$ of the initial weight within an hour in most grass pollens [81]. This water is typically lost through the apertures and the lost volume is compensated by a deformation of the grain shell. Not all grains present apertures but for aperturate pollen grains, the apertures fold inward during the drying process (c.f. Figure 5A) therefore sealing the grain and halting the desiccation [81]. This process is referred to as harmomegathy [82]. A large variety of closing typologies was presented in Halbritter and Hesse [83]. Mechanically this thin shell deformation is achieved by bending action. When allowed, bending is preferred to stretching in thin shell deformation. Energetically this preference is explained by the stretching energy scaling as the cube of the bending energy [84]. Couturier [76] presented an analytical model of pollen grain deformation with the assumption that a minor amount of stretching is tolerated and introduces a new type of mathematical surfaces useful for the analysis of thin shell morphings. This spherical folding mechanism represents an efficient amplification of the actuation created by the loss of water (Figure 5C).

At a larger scale, the seedpod of Vachellia caven exhibits an irreversible movement that involves a similar desiccation process of a doubly curved envelope [78]. The banana shaped pod presents a negative Gaussian curvature along the back of the pod. At the saddle point, the longitudinal and meridional curvature therefore have opposite signs. During desiccation the longitudinal curvature increases and the meridional curvature decreases (Figure 5D). This decrease triggers the opening of the pod and the release of the seeds. Similarly to the pollen grain, the mechanism has been modeled by isometric deformations of shells. Those analytical models have the same kinematic properties as the plant seedpod [78]. The analytical model could further inform the study of such pods (e.g., determining the amplification ratio of the mechanism).
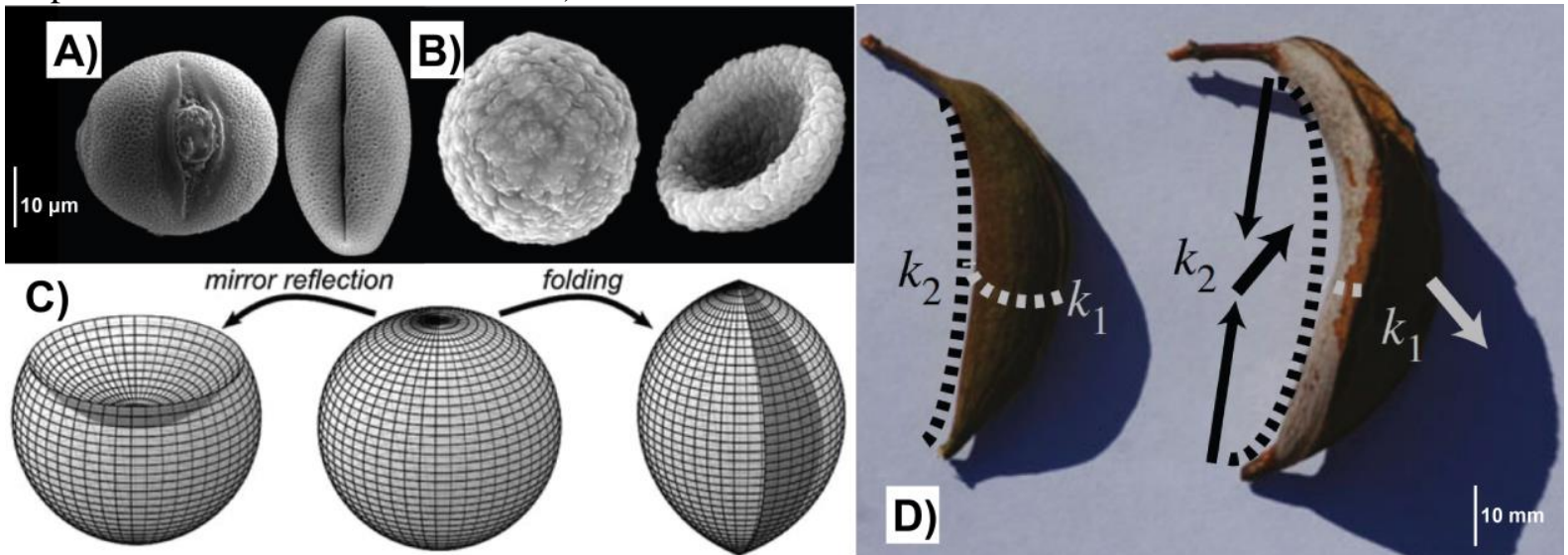

Figure 5 (A-B) Folding of pollen grains in hydrated (left) and dry (right) states - the pollen grain of (A) Euphoria milii folds on itself along aperture during desiccation (harmomegathy) while (B) Aristolochia gigantean shrinks by reflection of the surface (one of many possible ones) [76] - (C) Two bending-only, mathematical deformations of spheres correspond to pollen grain deformations [76] - (D) Variation of curvature in seedpod of Vachellia caven upon drying, meridional curvature $k_{1}$ decreases as longitudinal curvature $k_{2}$ increases. [78]

\subsubsection{Anisotropic layering in hydration-related expansion}

The second type of hydration deformation is controlled by differential anisotropic expansion within tissues. In pulvini, local water gradients create a bulging of targeted active cell layers. In contrast, dry cells of autonomous structures rehydrate uniformly when the water content in the environment increases. 
Strong anisotropies are present in autonomous structures creating in-plane bending, out-of-plane bending and torsion. A simple example of such construction is a strip of bi-layer laminate with the first layer composed of fibers in random orientations (isotropic) and the second layer with consistent fiber orientation across the width of the strip (anisotropic) (Figure 6A). The result of the swelling is an inplane bending of the strip. If instead of random orientations the top layer also receives an anisotropic, specific orientation, the strip of material can experience double curvature (Figure 6B) or even twisting (Figure 6C). Many seedpods implement such anisotropy to release the seeds [79, 85-87].

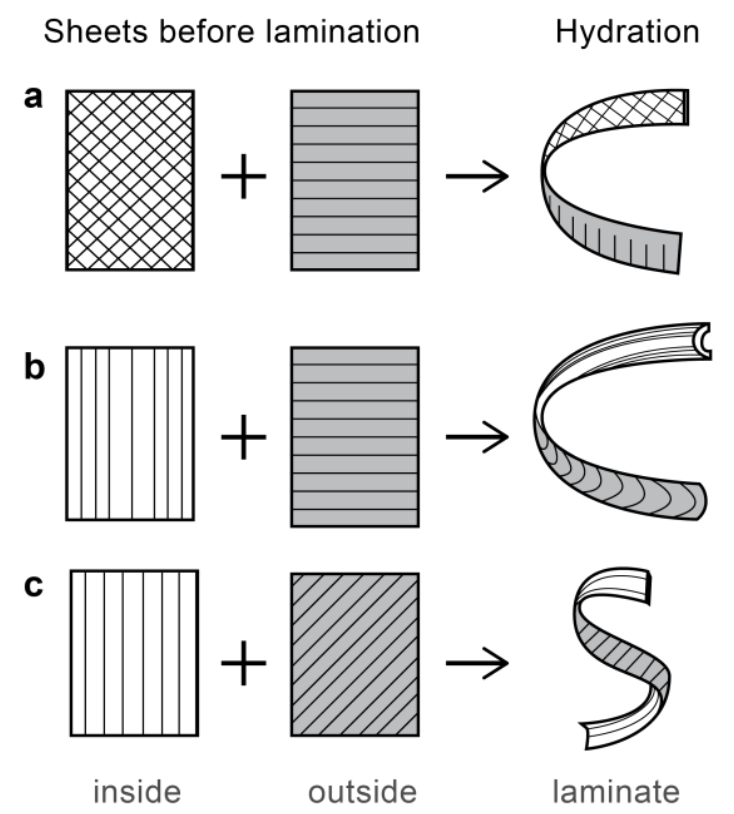

Figure 6 Laminate paper models of monomorph (a) and bimorph (b and c) hydraulic actuators. reproduced from [6]

This hygroscopic mechanism is the basis for the movement of three common seeds. The wheat seed (Triticum turgidum) has two awns on the seed dispersal unit, executing a uniaxial bending/straightening movement correlated to the diurnal air humidity cycle [88]. The awns are covered with upward oriented hair, which cause the seed to penetrate the ground during the cycles (see Figure 7A). This uniaxial bending movement is also found in pine cones (Pinus radiata $[9,21]$ ). In pine cones, this mechanism produces a remarkable KAR of about 160 [21].Two distinguishable material arrangements make up the large cone scales. The tissue presents a uniaxial bending fiber distribution with well-ordered straight fibers in the bottom layer and winding irregular fibers in the top layer [89]. The result is a closed pine cone when humidity is high and an opening movement as the air dries (see Figure 7B). The variation of angle is significant with approximately $50^{\circ}$ of range measured between the high and low extreme humidities [21]. A similar mechanism is observed in the geranium Erodium cicutarium whose seeds also present a self-burial movement due to the rotation of the awns. Due to a specific orientation of the material fibers, the awns coil when air humidity is low, and straighten when hydrated [90, 91]. This cyclical movement generates the burial of the seed (Figure 7C). 

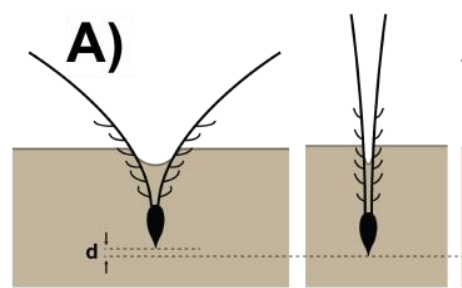

I. Day time

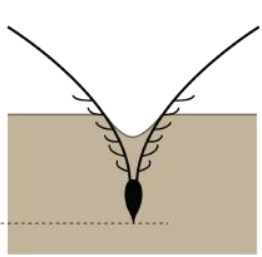

III. Day time
B)
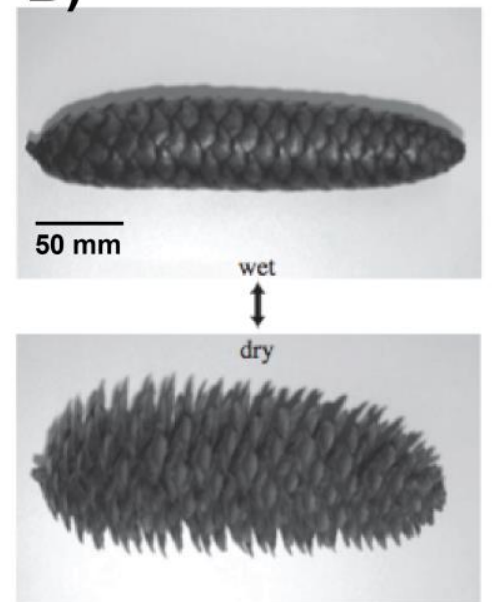
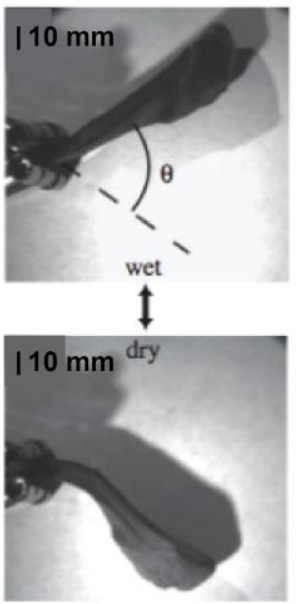

Figure 7 (A) Wheat awns cyclical burial movement - reproduced with permission from [88] (B) Drying gymnosperm cone- reproduced with permission from [92] and (C) Coiling Erodium seeds - reproduced with permission from [4]

\subsubsection{Fast release of stored strain energy}

In species presented by Skotheim \& Mahadevan [67] the time scale of this typology of movements is found between $10^{-3}$ and $10^{-5} \mathrm{~s}$. For similar smallest dimensions of structures, seed dispersal by fracture mechanism is faster than hydration-based and elastically instable movements [67]. Most explosive plants rely on storage of elastic energy in bent, pre-stressed or stretched members and its rapid release for dispersal [93]. The same principle of energy storage was used in bent wood in archery or in certain rock-throwing catapults before explosive-based weapons became the norm [50].

Several species in the genus Impatiens are known to present an interesting example of such an instant elastic energy release mechanism [94, 95]. One species, Impatiens glandulifera (Figure 8A) is an invasive species originally found in the Himalayas [96]. It is able to spread seeds up to two meters away from the mother plant via explosive dehiscence [97]. An external touch trigger causes the movement. The loculicidal seedpod is 1.5 to $3.5 \mathrm{~cm}$ long with longitudinal septa (seams) partitioning five valves. Each pod contains 4 to 16 seeds [98]. The valves are maintained in a straightened position by the connecting seam to the other valves. They are coiled in the relaxed state (see Figure 8B). The elastic energy stored in the seedpod originates from the bending deformation straightening the valves in the stressed position. This energy amounts to approximately $1 \mathrm{~mJ}$ [94]. In comparison, the energy stored in a bow before shooting the arrow is on the order of magnitude of $10 \mathrm{~J} \mathrm{[99].} \mathrm{The} \mathrm{kinetic} \mathrm{energy} \mathrm{transferred}$ to the seed represents about $70 \%$ of the total stored elastic energy [94]. This high proportion of kinetic energy transferred to the seeds makes the seed dispersal mechanism in I. glandulifera highly efficient. 

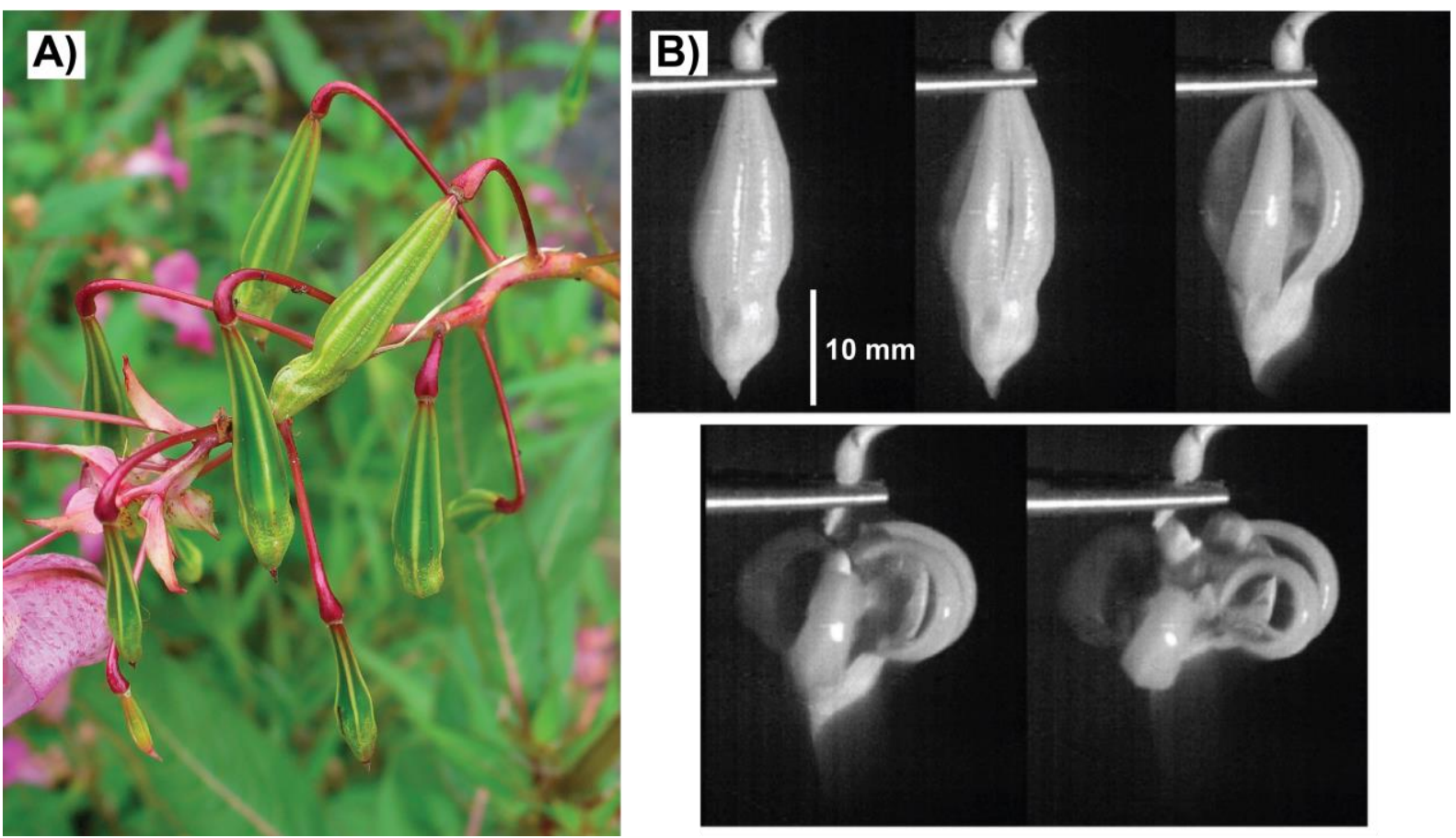

Figure 8 (A) Impatiens seedpods (B) explosive release of seeds [94]

The energy necessary to propagate the fracture along the whole length of the seam between the lobes is more than the total stored energy. However a finite element model of the system reveals that only about $30 \%$ of seam length between the valves is needed to actually hold the pod closed [94]. The system therefore gradually fractures along the seam before reaching the decisive part of the seam. At this instant the pod is the most sensitive to touch for explosion. The reason for this smaller fracture length is due to the shape of the valves that are linearly tapered longitudinally and transversally. This singular geometry influences how the valves are packed in the closed configuration. The elastic model of the valve as beams of varying cross sections indicates that they should interpenetrate themselves in the closed configuration [94]. Since this is physically not possible, the valves rest upon one another in the closed position, which makes the system extremely sensitive to modifications of any of its member. As soon as a valve deforms due to drying or to an external trigger, the geometry of the four other valves is modified, the seams break and the elastic energy is instantaneously released [94].

2.2.4 Kinematic amplification of external load by classical mechanisms and optimization of stiffness In certain cases, plant organs connected to the plant vascular system produce movements from the amplification of external forces created by pollinators or by repeated environmental stimuli ${ }^{2}$. They are passive movements. In flowers, the pollinator's weight generates actuation during visits. In these cases, pollinators of flowers have predictable landing sites on the flower. Strategies as evolved as ultraviolet guides [100], sexual deception [101] or precise guiding through the flower [102] are implemented to insure the spatial positioning of the pollinator. Such passive movements can be found in Calopogon tuberosus [103], Salvia pratensis [104] and Strelitzia reginae [105] for instance. The passive movement of Salvia pratensis is caused by a lever-type mechanism (see Figure 9) in which an insect attempting to reach the nectar cavity pushes the shorter arm of the lever with its head. In response, the longer arm is pushed on the pollinator's back and spreads the pollen on the insect [106].

\footnotetext{
${ }^{2}$ Pollinators can also be the source of active movements in flowers when sensors signal a presence. This phenomenon is discussed in Section 2.2.5.
} 

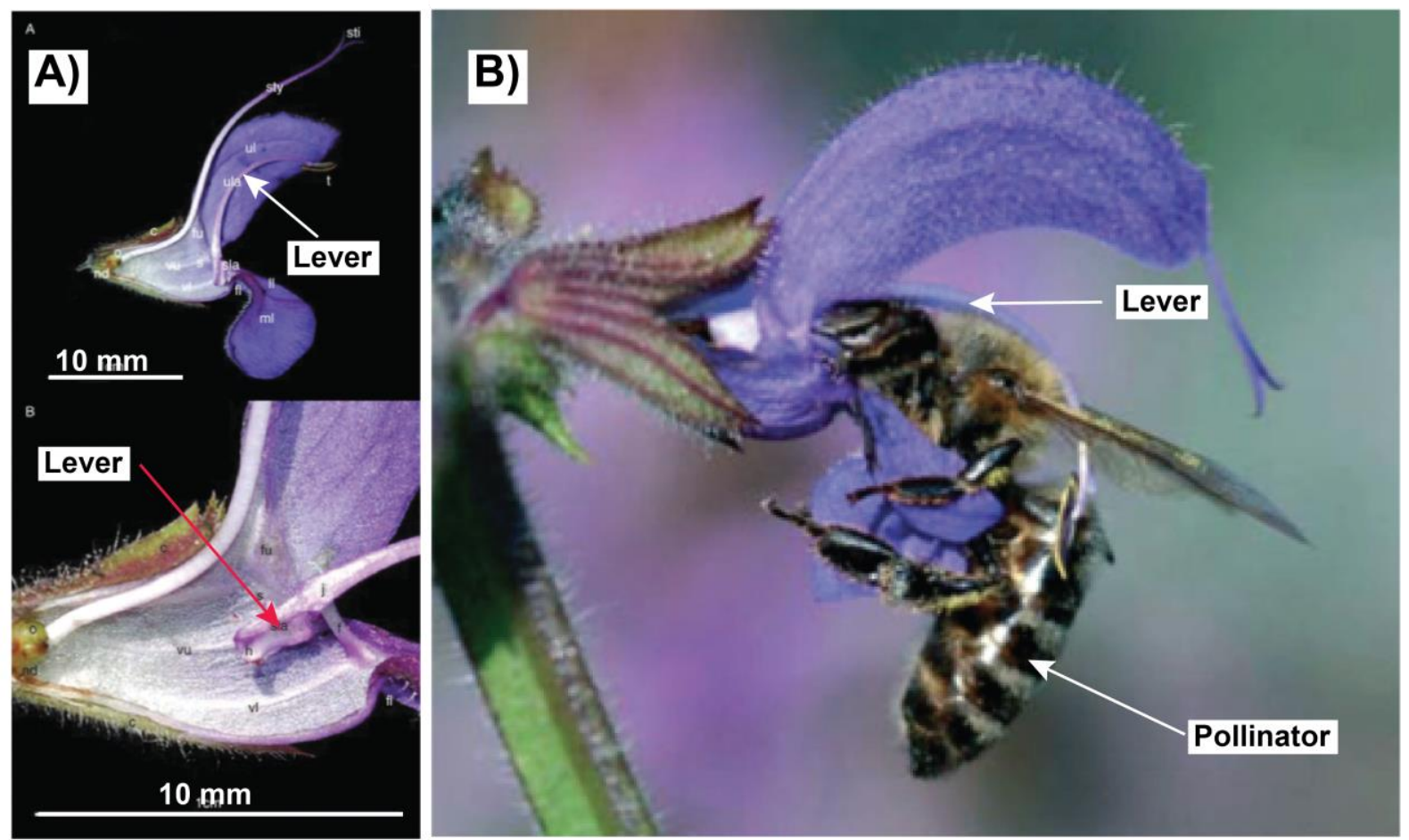

Figure 9 Lever of Salvia pratensis- (A) Longitudinal section with lever in the untriggered position (top) and detail in the triggered position (bottom) - (B) A pollinator activates the lever mechanism - reproduced from [104]

In Strelitzia reginae the movement of the flower is produced by a very different mechanism involving torsional buckling [107]. The flower has three orange sepals and three blue petals, with the latter having two fused together to form an arrow-shaped structure on which pollinators such as weaver birds come to land. The nectaries are located in the short corolla tube at the base of the three petals. The petals are attached to a long, fibrous rib [105] and when this rib bends down under the weight of the pollinator, the petals accommodate the deformation by rotating along the axis of the rib in a lateral torsional buckling mode, which exposes pollen [108]. This mechanism can be triggered many times without fatigue and has been used as basis for a bio-mimetic shading system [109].

Finally, passive amplification of external load can originate from a fine tuning of stiffness properties. The carnivorous pitcher plant Nepethens gracilis uses the impact force of rain droplets to propel ants from the underside of the lid covering the pitcher to the fluid-filled pitcher itself [110]. The lid is short and stiff and when hit by a droplet, it pivots around the hinged neck connecting it to the body of the pitcher. As a result of the form and structural compliant hinge, the lid produces peak inertia forces 19 times greater than the morphologically similar Nepenthes rafflesiana [111]. The underside of the lid, where ants shelter in rain events, is coated with low friction wax crystals, finalizing the trapping mechanism [111].

\subsubsection{Coupling of geometry and shell mechanics}

\subsubsection{Bilayer action coupled with complex shell geometry: Aldrovanda vesiculosa}

Aldrovanda vesiculosa is a small, rootless, aquatic carnivorous plant that floats freely in shallow, nutrient poor waters from eastern Europe to Australia [112]. The plant exhibits repetitive growth patterns with 6 to 8 leaves radially attached to the stem in a spoke-like geometry [113]. Each leaf terminates in a trap measuring 3 to $6 \mathrm{~mm}$ long and consisting of two lobes connected by a midrib. The traps elastically deform in a hinge-less mechanism. The deformation is caused by the bending of the central part of the shell (midrib), with the actuation produced by motor tissues located in both lobes along the midrib [114]. Iijima and Sibaoka [114] reported that the motor cells have their longer axis oriented perpendicular to the midrib, indicating that their radial expansion is the source of actuation. Additionally, the motor cells in the motor zone are distributed in three layers: inner epidermis, outer epidermis and a middle layer. Sibaoka [115] hypothesizes that during firing the inner layer of the motor zone becomes flaccid while the outer layer remains turgid. As a result of this variation in stiffness the midrib bends toward the inside 
of the trap. This is a first amplification of movement implemented from bilayer effect. Interestingly, the actuation of the trap is amplified a second time by the double-curved shell geometry of the trap itself. The marginal zones located away from the midrib are non-motor but their doubly curved geometry accommodates the bending of the midrib by creating a folding motion of the lobe on itself. Numerical models of the geometry and actuation [20] confirmed the hypothesis that the fast closing (100ms) of the trap is due purely to swelling and shrinking and does not involve shell buckling. Poppinga and Joyeux [20] showed that the amplification ratio of the trap closing displacement (output) over the reduction of distance between the ends of the midrib (input) nears 200. This extremely efficient amplification demonstrates both the high potential of combining several kinematic amplification strategies and the potency of shells for kinematic amplification.

\subsubsection{Progressive change of curvature: pollination of flowers}

The flowers of certain plant species implement active movements to perform efficient cross-fertilization. In the case of the orchid family (Orchidaceae), about one third of species implement pollination by deception [106, 116], which consists of pollinator attraction without providing a reward. 2.2.5.1 The principle of this movement resembles the passive displacement of the lever found in Salvia pratensis. However, by actively generating the movement, the flower does not depend on the action of the pollinator beyond triggering [117]. Examples of such movements can be found in species of the Australasian orchid genus Pterostylis such as Pterostylis sanguinea [101] or in Pterostylis longifolia $[118,119]$. In the fastest cases, the time-scale for those movements is ten milliseconds [120]. In general, the resetting time is several orders of magnitudes longer than the trigger time, as seen in Pterostylis [101]. In addition, a large number of repetitions tend to damage the mechanism[101].

A relevant example of this strategy is seen in another genus, Stylidium, which carries the common name triggerplant. The column that carries both stamens and style of the flower is mobile. In a large rotational movement of the column triggered by touch, pollen is deposited on the insect. This insect will in turn visit other flowers effecting in cross-pollination. [120]. The active column consists of two distinct parts: the active and the passive part (see Figure 10A). The active part, termed the bend, is easily identified due to the curved rest state, different color and change of sectional curvature during the firing. The passive part of the column remains straight during the movement and does not vary in cross section during the movement [120]. Upon triggering, the active bend of the column changes longitudinal curvature that creates a rotation of more than $180^{\circ}$, carrying the anthers towards the pollinator (see Figure 10B). The entire movement happens in a time span of 10 to $30 \mathrm{~ms}$ [120] which is among the fastest movements reported in [67]. The mechanics of this movement are based on turgor pressure variations but have not yet been clearly described.
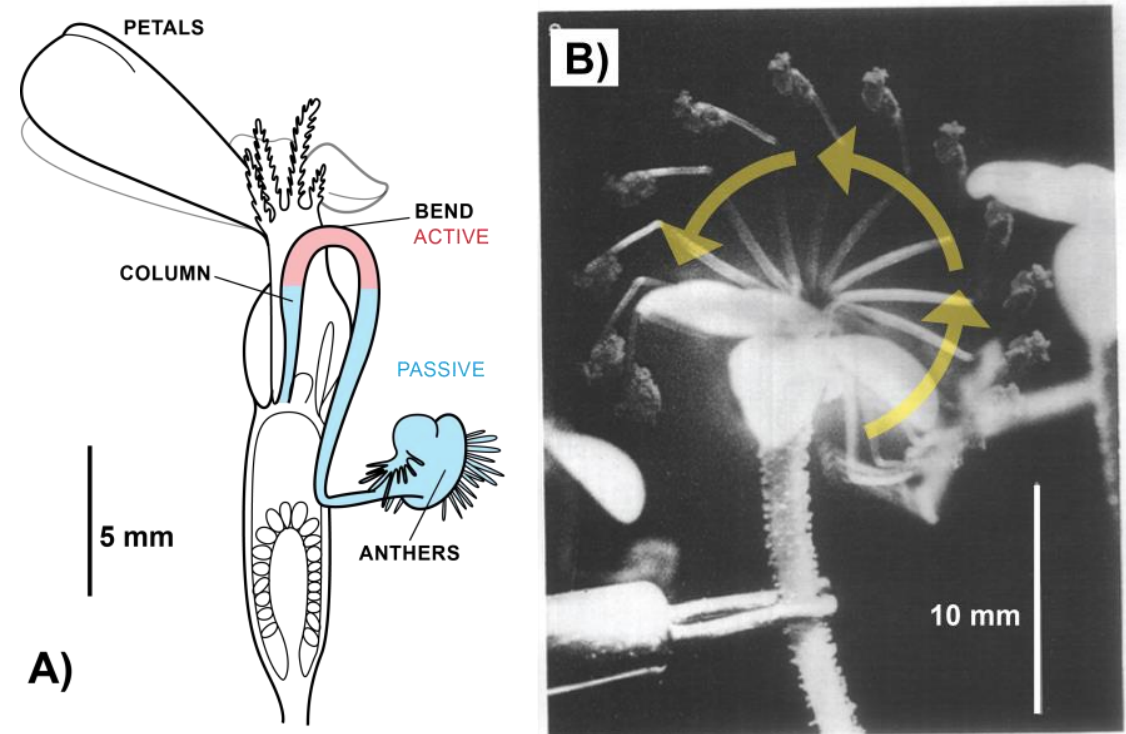

Figure 10 (A) Diagram of flower of Stylidium graminifolium in median longitudinal section with scale of 5 mm - (B) Photography of the firing of the column of Stylidium crassifolium - reproduced with permission from [120]

With a mechanism which allows for motion faster than dictated by the poroelastic timescale described by [67], the Stylidium species implement an elastic instability. Overall, there are three mechanical levels 
involved in the rotational movement of the bend [121]. Cell expansion is the first level: turgor pressure increases in specialized section cells of the bend that deform longitudinally. In the second structural level, the heterogeneity of the section with cells that either expand or do not, create a bilayer effect. Finally in a third level, the curvature of the bend's section is reversed during firing.

Levels 1 and 2 comply with the poroelastic theory since they are based solely on fluid transport in the material. The main process speeding up the motion of the column occurs at level 3 . This multilevel mechanism illustrates the coupling of several mechanical principles in a natural material, the bi-layer effect (structural levels 1 and 2) present in many pulvinus-based plant movements (as seen in [67]), typically Mimosa pudica [68] or Codariocalyx motorius [122], and an efficient elastic mechanism (level 3 ). This latter mechanism is not clearly understood. The shell structure model proposed in [123] hypothesized a sudden and complete loss of stiffness of the bend of the column as source of its rotation. However this reasoning can be challenged. The turgor pressure in the active cells of the bend increases during the deformation [121]. As reported in section 2.1, the elastic modulus of the material increases with an increase of turgor pressure. A quasi-spherical deformation occurs in the cells of the bend tissue in Stylidium species [121]. The active cells of the bend appear to elongate radially as well as longitudinally [123] in the posterior layer of the section's core. The result is a change of transversal (or sectional) curvature in the bend. This change of curvature of the section from concave to convex during the swelling of the cells is due to the increase of radial cell volume on the concave side of the bend (see Figure 11) [121]. The progressive change of this section's curvature along the bend coupled with the curved longitudinal geometry of the bend creates the fast movement of the column. Interestingly, the layout of Stylidium motor cells with their long axis perpendicular to the plane of the sectional curvature is similar to the midrib cellular layout in Aldrovanda vesiculosa. In that plant, the cells' long axis is oriented perpendicular to the midrib. The radial expansion of the cells over the length of the midrib creates an in-plane inversion of the midrib curvature. This mechanism is similar to the mechanism at play in the posterior layer of Stylidium's active bend section (Figure 11) this sees a curvature inversion in the section's core.

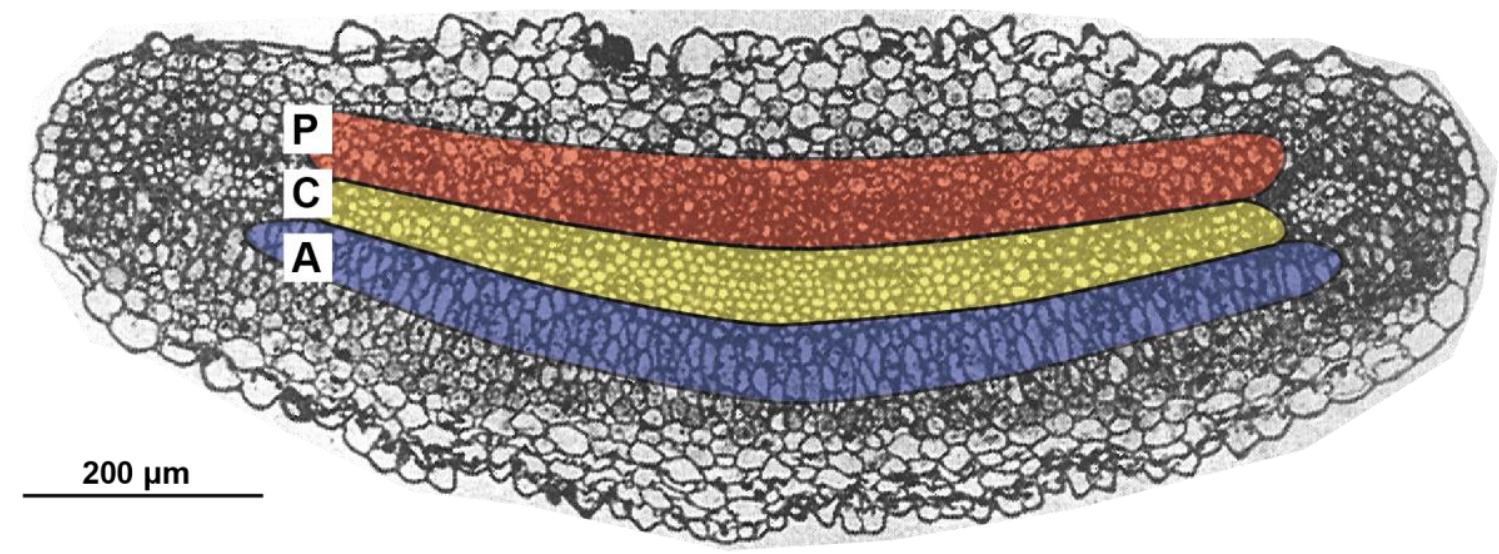

Figure 11 Transverse section of the bend of $S$. crassiferum [120] with highlighted structural core cells- The section's concave curvature appears in the posterior $(\mathrm{P})$, central $(\mathrm{C})$ and anterior $(\mathrm{A})$ of the core.

\subsubsection{Snap-through buckling in carnivorous plants}

Pursuing the goal of caching prey to compensate poor nutritional habitats, Dionaea muscipula has evolved adaptive digestive enclosures based on a shell-buckling phenomenon. This movement is not unique in carnivorous plants. Utricularia inflata also has enclosures triggered by prey [124-126]. The mechanics of $D$. muscipula have been extensively documented in literature in [20, 127-133].

D. muscipula implements a type of elastic instability called snap-through buckling characterized by a rapid change of geometry of a system between two equilibrium states [134]. The bi-lobe traps are located at the end of the leaf blades, and are triggered by repeated stimulation of three sensing hairs on the internal surface of each lobe [131]. They are set off by repeated contact of a prey with a trigger hair on the internal surface of the lobe [130]. The number of contacts of the prey with the hair has been shown to have a direct impact on the behavior of the trap. Two contacts at 30s apart are necessary to cause the closing of the trap, five contacts in total are required to fully start the costly digestive process [133]. After the first two contacts, the trap closes. It will remain in a semi-closed state with the cilia (long hairlike structure) on the edge of the trap forming an enclosure holding any larger prey securely [131]. More 
contacts signal the presence of an nutrient-rich insect and the plant eventually start the digestive process [133].

From a mechanical point of view, the mechanism driving the rapid closing of the trap has been described in a number of studies $[20,128,130]$. The elastic phenomenon that dominates at the larger structural level, is the buckling of a doubly curved shell [20, 128]. This buckling is caused by a bilayer effect [130]. Geometrically, a two-step sequence is observed. When the traps are in the rest position, the mirroring lobes remain in a state of positive average curvature. After being triggered, the lobes undergo a radical change of geometry, shifting from a positive to a negative average curvature [128]. Each lobe presents two main curvatures, which are described with respect to the midrib of the trap joining the two lobes. The curvature transversal to the midrib, changes sign during closing of the trap while the longitudinal curvature does not [128]. The transversal change of curvature drives the closing movement of the trap [128]. This change of curvature is generated by a bilayer effect in the two-layer structure of the lobe tissue, and has been described in a number the studies [127, 130, 135]. The inside of the lobe (called the "upper layer") remains under high turgor-pressure at the rest state, creating a convex lobe geometry. The closing movement is triggered by the gradual de-pressurization of the upper layer and the increase of turgor-pressure in the exterior side ("bottom layer") of the lobe [130, 135]. The bottom layer experiences an increase of length in the transversal direction [128]. This elongation is supported by observations of the microstructure of the bottom layer material, which is comprised of cylindrical cells. These cells have their long axis oriented in the direction transversal to the midrib and are reinforced with hoop-like, cellulose reinforcements [135]. From an energy perspective, the lobes of the plant produce a large release of elastic energy during the closing [20]. This release coincides with the buckling phenomenon [20] and the rapid change of curvature. As measured in [128], 60\% of the total displacement happens during this rapid phase (1/10 of the movement's duration).

\section{Embodied natural principles in engineered mechanisms}

Manmade, automatically moving devices usually include a deployment system and an actuating element, which converts an input energy into mechanical energy. Those systems are often discrete and composed of rigid moving parts (e.g. pantograph) [108]. But in some cases, the actuator can be embedded into the system: a subcategory of movements called morphings presents the characteristics of continuous change of shape not by involving discrete part movements but with deformation of the entire structure upon actuation [2]. Various transduction mechanisms based on physical phenomena, such as electromagnetism, combustion, thermal expansion, static electricity, Joule effect, fluid pressure, or phase changes, can be at the origin of the actuation [108]. A non-exhaustive list of actuator types used in engineering or research application includes: electrical motors (electromagnetic actuators), combustion motors, pneumatic actuators, hydraulic actuators, electrostatic actuators, thermal actuators (thermal expansion and bimetal effect), electro-thermo-mechanical actuators (thermal actuators heated by Joule effect), piezoelectric actuators, shape memory alloys, dielectric elastomer actuators, magnetostrictive actuators, chemical actuators and capillary force actuators [136].

\subsection{Comparison of movement in morphing structures and in plants}

Features of an actuator, depending on the physical phenomenon involved and on the materials used, include stroke / rotational amplitude, torque / force, blocking force, speed of response, operation speed, precision, power consumption, compactness, energy density, silent operation, and lifetime span [108, 137]. This section focuses on actuator displacement characteristics and in particular stroke or rotational amplitude. In order to study the parallels between engineering device movements and plant movements, it is crucial to select relevant actuation typologies. Combustion motors and electrical motors rely on wheels and rotation axes: these elements are purely human engineered designs and are not present under this specific form in the plant world. For this reason, traditional motors will not be discussed here. The discussed actuators operate without complex mechanisms and transmission systems including hinges, articulations and gears, which again are not present in plants. Physical phenomena triggering the actuation are closely linked to the properties of the materials constituting these actuators. Such phenomena include electric conductivity, thermal expansion, fluid compressibility and thermomechanical behavior. Some morphing systems already implement merged structure and actuation. The seamless embedding of the actuation in the morphing structure is one of the characteristics of plants movements. 
Such engineered structures are very common at the micrometer scale, in micro-electro-mechanical structures (MEMS) because it is difficult to manufacture hinges, articulations and gears, and even impossible to manufacture electric motors at such small sizes [138]. One aspect shared by MEMS and actuators in nature is their frequent ability to both sense and actuate, because the physical phenomena behind actuation often have a direct and a converse effect: the Peltier effect and the Seebeck effect, the direct and converse piezoelectric effect. The engineered device thus becomes simultaneously an actuator, a structure and a sensor. Tremendous progress has been made in this area in the last decades, along with the advances in materials science and often with bio-inspired principles [139]. However, microscale structures cannot always be reproduced at a mesoscopic or macroscopic scale. In the case of a simple beam, the strength varies linearly with a linear dimension while the volume has a cubic variation with this same dimension. As a consequence, insects are often much stronger than bigger animals in terms of force per body weight [138]. The comparison between plants and engineered smart structures also relies on the similarity of the materials involved. Ashby's material property charts [140] particularly illustrate the proximity of the Elastic modulus versus Density values for natural materials, and for polymers and composites, which are frequently used in morphing structures (Figure 12).

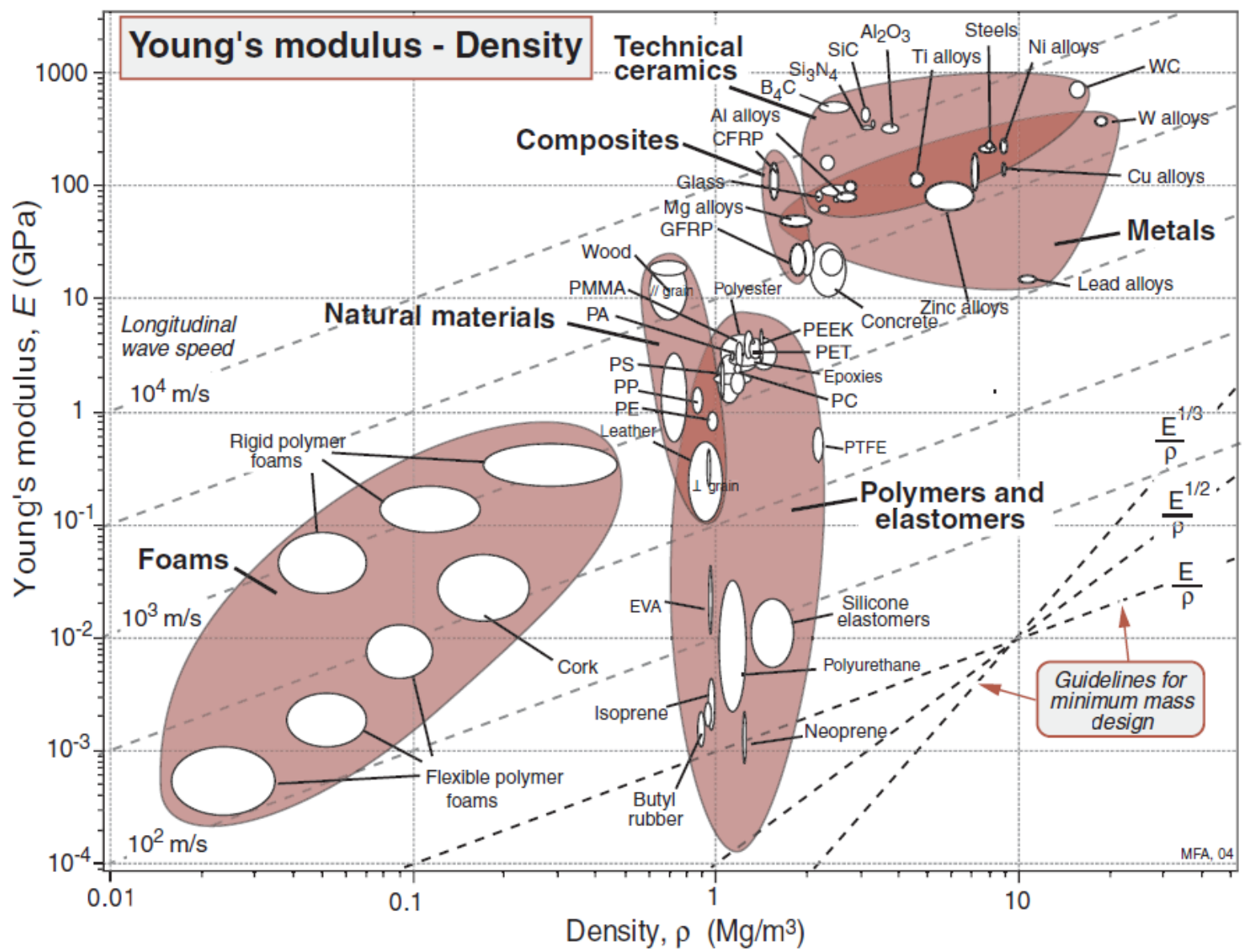

Figure 12: Material property chart (Elastic modulus versus density), reproduced from [140]with permission from Elsevier

Most of the small- and large-scale actuators rely on the same physical phenomena and have a common characteristic; they generate small movements, and the output displacement - or the output rotation sometimes needs to be amplified. Various movement-amplification strategies can thus be identified by reviewing different scales (from the micrometer to the meter) and different material properties.

\subsection{Different strategies for transforming a small deformation into a large displacement}

Four basic types of kinematical amplification strategies are listed: geometrical strategies, variations of material properties, harnessing the properties of fluids, and energy storage. In section 3.3 it will be shown that these strategies can efficiently be combined together. 


\subsubsection{Geometrical strategies}

The most common geometrical strategy for kinematical amplification is the discretization of a system into distinct elements. This leads to kinematics that can be compared to rigid-body mechanisms. The lever is probably the simplest geometrical movement amplification mechanism, cited as the most important of the five elementary machines by the $18^{\text {th }}$ century scientist Ephraim Chambers in [141]. Plants are also able to implement this mechanism (see 2.2.4). A hypostatic beam with one single simple support transforms a large force close to the supporting pivot into a large displacement with small force output, at a large distance from the support. This basic principle is at the origin of various kinematical amplification mechanisms, such as the scissor, the X-frame ([142, 143]) or umbrella mechanism [144]. In [142], the scissor mechanism is identified as the best amplification strategy for the design of a trailing edge servo-flap actuated by a piezoelectric ceramic stack in helicopter rotor blades due to the small form factor (i.e. a large stroke and a compact structure), simplicity, a highly linear operation and an appropriate frequency bandwidth. The prototype features a KAR of 15.2.

In [145], the thermal expansion legs connecting a micro-actuating beam with two anchoring pads are manufactured with a small in-plane angle in relation to the anchoring pads perpendicular direction (Figure 13), so that a significant kinematical amplification is reached as long as this in-plane angle is smaller than $45^{\circ}$. This angle limit for displacement amplification can be easily found geometrically. Upon thermal actuation by an electrical current, the legs expand, and because of the zero-displacement boundary conditions imposed by the anchoring pads, they rotate and thus set the central beam in motion. Thus, the output deflection in the direction of the longitudinal axis of the beam is greater than the deformation in the direction of the longitudinal axis of the legs. This device is sometimes called a pyramid actuator and has to be carefully studied before implementation because of the snap-through risk ([142]).

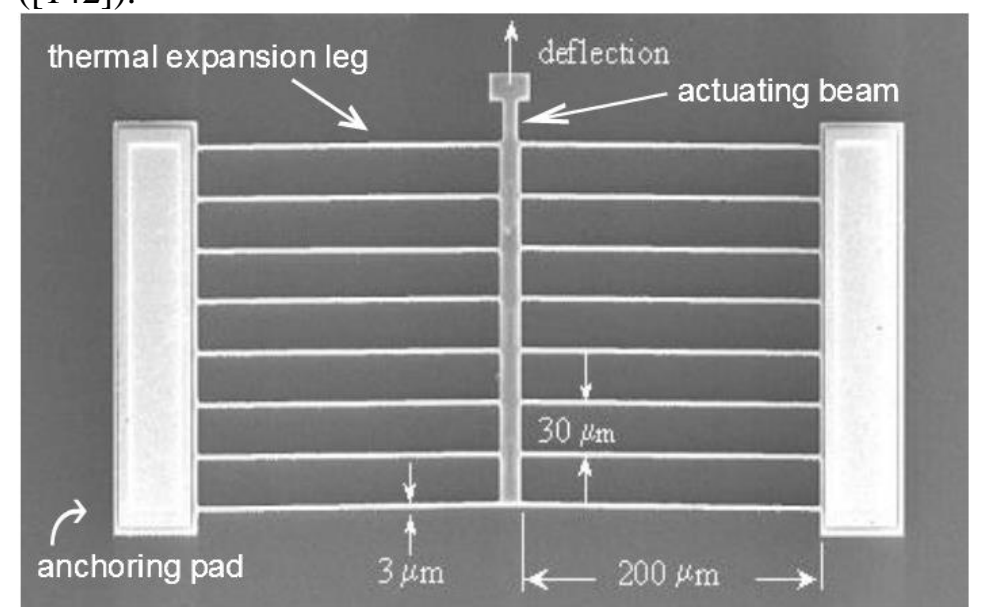

Figure 13: Linear thermomechanical in-plane microactuator, adapted from [145] with permission from Elsevier

Contemporary computational optimization tools offer interesting perspectives in geometrical optimization of flexible smart structures. Masching and Bletzinger ([146]) developed "parameter free" structural optimization techniques. The optimization runs directly on the finite element mesh nodes coordinates instead of the design parameters in order to produce geometries that react efficiently to the actuation solicitation for "optimal actuation" morphing structures. These "optimal actuation" structures deliver a maximum displacement output for a minimal actuation input.

The geometrical discretization also encompasses another widespread strategy: With the use of smalldisplacement actuators, kinematical amplification can simply consist of the concatenation of various identical actuators. In [147], multiple bridge-type mechanisms (Figure 14) with piezoelectric actuators are assembled in series within a compact "cellular" architecture where the amplified outputs (vertical displacement) are added and provide the input of larger bridge-type mechanisms whose horizontal outputs again put a third mechanism in motion. In this system an actuation output displacement of over $1 \mathrm{~mm}$ is achieved, while the piezoelectric actuator exhibit an output displacement of $45 \mu \mathrm{m}$ : this amounts to a KAR of about 25. 


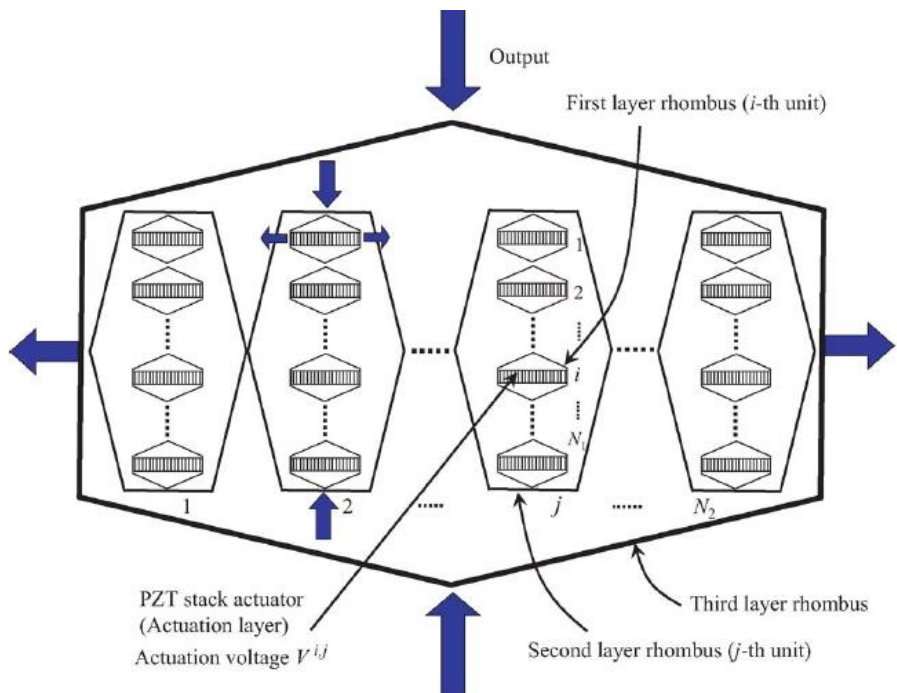

Figure 14: Large stroke piezoelectrical actuator, reproduced from [147]

In [148], a space deployable and adaptive structure inspired by the bilayer effect caused by the differential turgor pressure in plant cells (see 2.1.2) is proposed. An array of inflatable cells connected by MEMS valves with a central electrical command can change its curvature or reach more complex shapes by inflating or deflating specific cells. This strategy of adding the effects of multiple actuators proves itself resilient because single elements can fail without compromising the global behavior of the system.

Another, more advanced geometrical strategy is the kinematical amplification through elastic deformation of a continuous element. Sufficiently important shape changes can lead to elastic instabilities like buckling: often avoided in engineering, these mechanisms can provide significant amplifications. In [137], a flexible buckling beam acts as an amplification system for a piezoelectric actuator by transforming its small linear displacement into a large rotation of the beam for dynamic applications. In [149], the mechanical behavior of a carbon fiber reinforced plastic flexible structure composed of two connected shell lobes and providing displacement amplification is studied. Such a shell buckling kinematic is inspired by the shape and deployment of Aldrovanda vesiculosa described by Poppinga and Joyeux [20]. The non-linear behavior due to the large displacements, and, more specifically, the influence of these non-linearities on the stiffness of the structure, are discussed next. The variations in different stiffness components (i.e. elastic, geometric and shape-related stiffness) during deployment highlight an increase in the global stiffness response induced by the shape changes during a first deployment phase, and then induced by the development of tensile surface stresses in the second phase.

\subsubsection{Variation of material properties}

Controlling the stiffness of different regions of the structure or different material directions of the structure is a common strategy for hingeless movement amplification. In order to design advanced materials with mechanical properties control, one can take advantage of bio-inspiration. To that extent Saavedra et al. ([150]) showed that nature implements multiple stiffness variations, in time, in space, at various scales, during loading and during external conditions changes. Three sub-strategies can be distinguished, namely: continuous or discontinuous variations of material properties, and material anisotropy.

The first sub-strategy, a continuous variation of properties, is often seen in compliant mechanisms: a whole deployable structure can be manufactured as a single element, including hinges and springs, by locally varying the material thickness or stiffness. In [151] and [152], compliant movement amplification mechanisms are presented, where the amplifying structure is separated from the piezoelectric small-stroke actuator. In Figure 15, eight links behaving like rigid bodies combined with eight small-section zones acting as flexure hinges form a bridge-type mechanism made of a single material. This structure is used for dynamic amplification: the horizontal linear input actuation realized by the piezoelectric stack is transferred by the structure through the flexure-deformed hinges to the 
central links, producing a vertical output displacement. A KAR of 16 to 17 has been experimentally reached.

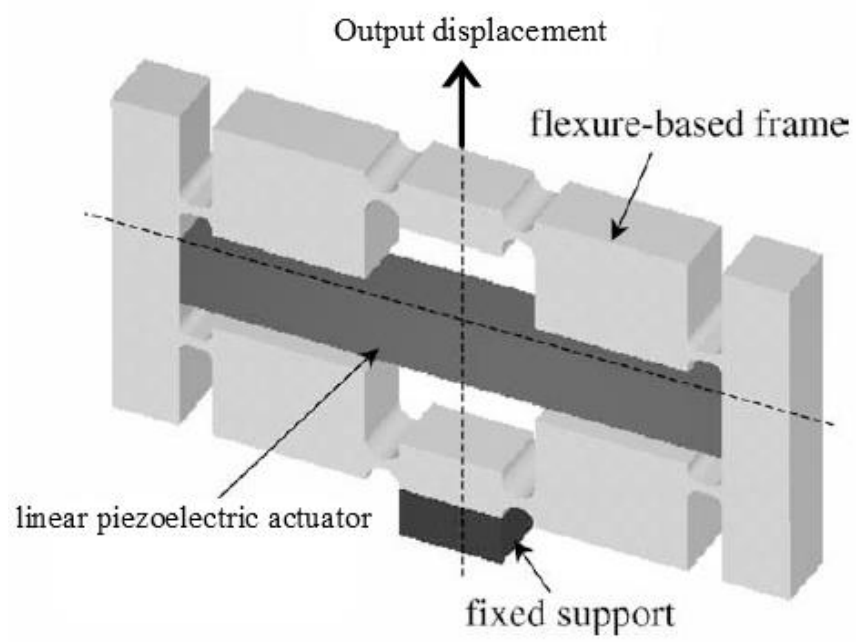

Figure 15: Bridge-type mechanism, adapted from [151] with permission from Elsevier

The second sub-strategy, namely spatial discontinuities in material properties, is mostly observed in heterogeneous multilayered materials. Bi-layered material structures (e.g. bimetals) are similar to the basic movement generation developed by plants. By exploiting a differential thermal (or hygroscopic) expansion behavior in two or more layers, which are structurally bound together, one can develop large displacement structures with original deformations. This actuation principle is widely used in manufactured goods, and commercial bimetal products present a KAR of up to 140 with the best couple of alloys, when comparing the total extension of the active metallic layer and the output deflection [22]. As this technology is highly precise and reliable, it is frequently used at MEMS scale, for example in designing electro-thermal micro-grippers (see [153]). It is implemented in high-precision positioning applications like in [154], where such bi-layered structures achieve tilting angles up to $30^{\circ}$ in order to rotate a micro-mirror. This electrically actuated optical device is hung on a portal structure made of a horizontal rigid beam and two supporting bilayer studs consisting of a silicon layer and a nickel layer in opposed arrangement on both sides. The nickel layer has both functions of thermal expansion layer and electricity conducting layer for heating. Besides being the support structure, the bilayer studs are therefore also actuators.

At an architectural scale the installation "Bloom" ([155], Figure 16) (Doris KIM SUNG Studio Architecture, 2011, Los Angeles) has been realized with thermo-bimetal elements to create a zeroenergy active skin. The surface of this "breathing skin" is made up of approximately 14000 laser-cut bimetal pieces, creating a complex form that was computationally designed. Each skin element can curl with various and optimized radii, using the thermo-elastic properties of bimetal. Either with a function of sun-tracking either with a function of natural ventilation, the whole installation is optimized for a peak performance at spring equinox.

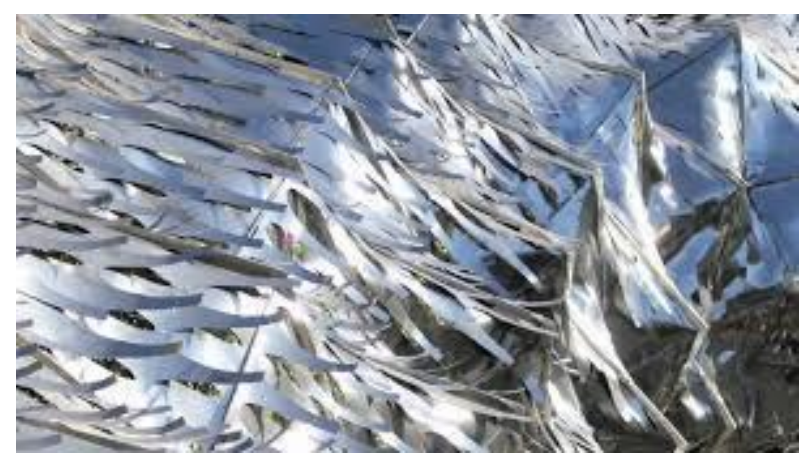

Figure 16: Doris Kim-Sung, "Bloom" installation, view of different tiles curling the skin 
The last substrategy of material properties control in a structure for displacement maximization is anisotropy. If each direction in a material has its own properties, such as in fiber reinforced plastics (FRP), different displacements including curling, twisting as well as various buckling modes) in specific directions can be combined with structural properties (such as strength and fatigue strength, stiffness, flexibility and dynamic behavior) in other directions to design lightweight efficient structures. In [107], a bio-inspired deployable structure is proposed as a shading device. The glass FRP wings undergo lateral-torsional buckling, in order to deploy into a doubly curved shape during the actuation of a central bending beam element. This mechanism is directly inspired by the petal opening movement of Strelitzia reginae (cf. Section 2.2.4). The high strength of the glass fibers is combined with a highly flexible epoxy resin in order to achieve a low bending stiffness and, at the same time, structural resistance to wind loads.

This lateral-torsional buckling has also been implemented as a morphing strategy for a kinetic skin at a larger scale for the main entrance façade of the "One Ocean Pavilion" ([156]) (SOMA , EXPO 2012, Yeosu, South Korea) (Figure 17). On the length of the façade (approximately 140 meters), each of the 108 morphing lamellas work from bottom to top with a span varying between 3 and 13 meters. Each individual modular lamella is moved by actuators located on the upper and lower edges of the facade. The lamellas are composed of glass fiber reinforced polymers conferring them the required characteristics: a high tensile strength combined to a low bending stiffness, allowing large elastic deformations. Due to a pre-curved and asymmetrical shape of each lamella, the bending resulting from the actuation generates a side rotation of the elements. This rotation allows variable lateral openings which are used to control the lightning conditions of the interior spaces.

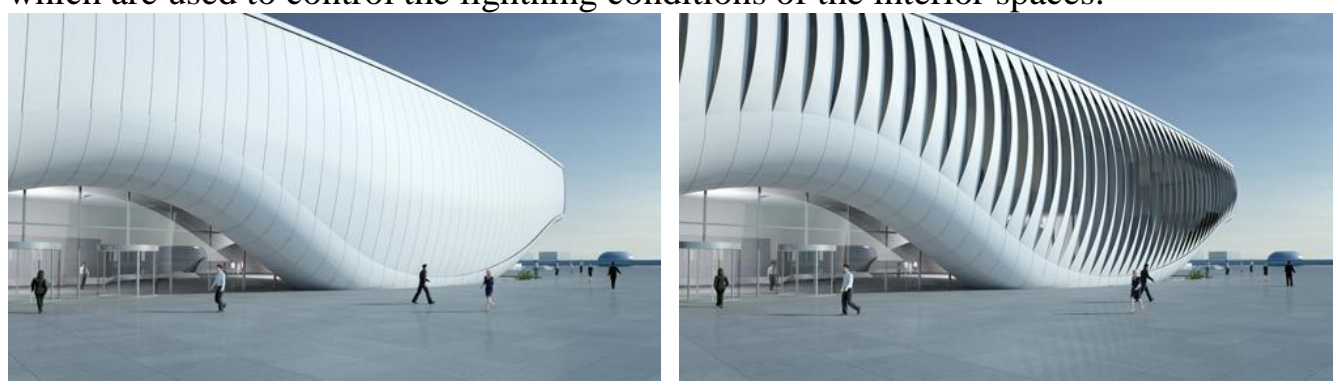

Figure 17: Kinetic skin in closed and open positions, One Ocean Pavilion, Yeosu, South Korea

\subsubsection{Fluid compressibility and incompressibility / Swelling and Shrinkage}

Harnessing the properties of fluids can also lead to kinematical amplification in structures. Hydraulic structures use a fluid incompressibility, whereas pneumatic structures use air compressibility to produce a displacement. In the "Sunfolding" device [157], pneumatic polymer structures actuated by differential pressure enable large rotations of the supporting structure of a solar panel for sun-tracking purposes. This strategy eliminates traditional mechanical elements like hinges, gears or articulations. The differential pneumatic expansion employed is similar to the planar pulvinus-generated movements of Mimosa pudica's secondary pulvinus presented in 2.2.1.2. At a smaller scale, the incompressibility of an encapsulated glyceric fluid is exploited and combined to a piezoelectric actuator for displacement amplification in tactile Braille displays ([158], Figure 18). The glyceric fluid fills a space between two highly deformable thin polydimethylsiloxane membranes, this space being much larger on the actuation side which is in contact with the piezoelectric stack, than on the display side. Upon piezoelectric actuation, the lower membrane surface pushes the fluid to the display side, leading the fluid to locally curve the display membrane into a bump which the finger can feel. The KAR can thus be optimized up to a value of 15 . 


\subsubsection{Energy storage}

The last way of amplifying a mechanical input is to store energy in order to produce a larger mechanical output (displacement or force) by releasing this energy in a short time step (short in comparison with the energy accumulation duration). In engineering, this type of mechanism is often seen in deployable structures and in bi-stable mechanisms, with two different functional shapes $([159,160])$. Deployable structures can exist in a compact state of high or low-energy, for instance for transportation purposes, and on the other side in a low-energy deployed state, usually of a larger size. Bi-stable structures present two different low-energy stable shapes and can switch from one to another by passing through a highenergy, unstable state. In both cases these movements happen with a hinged mechanism and/or elastic deformation. Mixing these two principles, in [161], a bi-stable deployable arch made up of scissor mechanisms is proposed. This system presents two low-stress states: compactly folded or deployed shape. It moves from one to another by a snap-through phenomenon due to geometric incompatibilities between the hinged rod members. The incompatibilities generate elastic strains in the rods, storing energy in the high-stress-state structure. Its behavior has been modeled both in the stable states and during the deployment process, leading to a design trade-off between flexibility in order to ease deployment and stiffness for the stable shapes.

\subsection{Coupling of strategies for movement amplification}

The four kinematical amplification strategies presented in sections 3.2 (Geometric, material properties, fluid incompressibility/shrinking and swelling, energy storage) can be combined with each other in order to create even greater amplification factors or more efficient mechanisms. This combinatory approach can be compared to plant movement strategies where several mechanisms are combined (e.g. differential turgor pressure in cells and elastic instabilities) to create one movement. The following selection presents a non-exhaustive list of interesting couplings.

\subsubsection{Thermal actuators using heterogeneous multilayered materials and geometry to amplify thermal} expansion

Bi-layer thermal expansion structures bend in one or two directions. But by exploring more complex material arrangements, one can obtain infinite deployment patterns.

In [162], a range of bi-material beams is simulated numerically in order to study the influence of the initial cross-section geometry on the deformation patterns after actuation: bending, helical and twisting patterns can be obtained. By varying the two-dimensional distribution of the materials in the crosssection, without variations in the longitudinal direction, it is shown that even with simple geometries, complex 3-dimensional movements can be produced, and that these phenomena are highly dependent on the cross-section symmetries (Figure 19 \& Figure 20). 

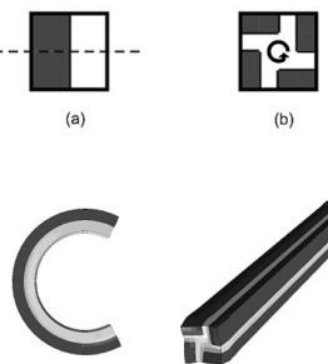

(b)

(a)

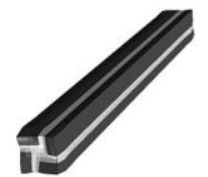

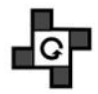
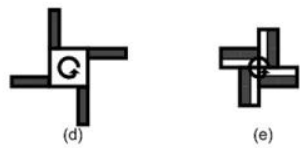

(e)
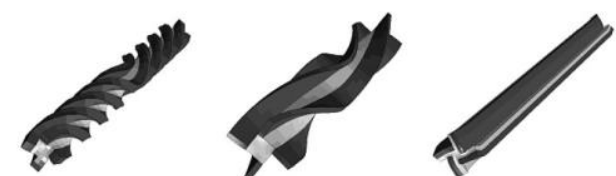

Figure 19: Bi-material beam simulations, reproduced from [162]

These principles can be exploited for engineered hydrogel actuators, a promising research field for medical applications [19, 163], and for optical microscale actuators [154, 164].

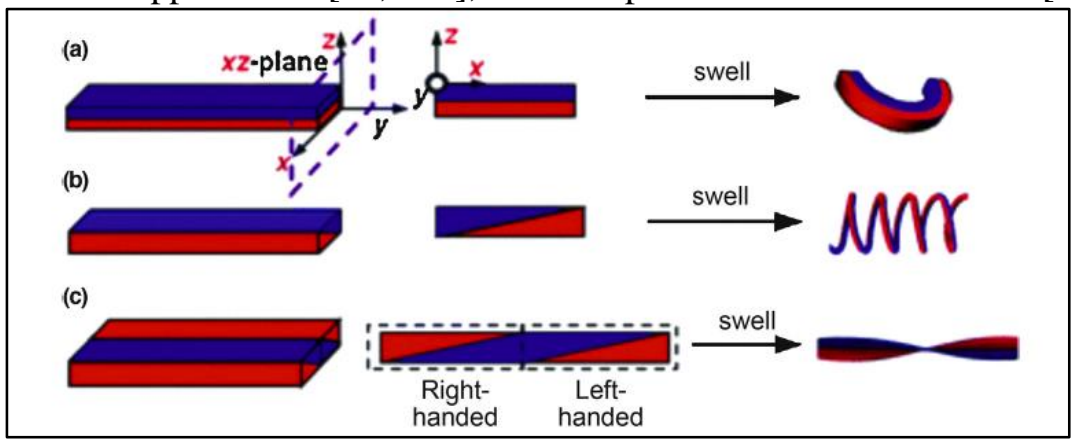

Figure 20: Hydrogel actuators with different cross-sections, reproduced from [163] with permission of The Royal Society of Chemistry

\subsubsection{Snap-through phenomenon: variation of properties and energy storage}

Snap-through mechanisms exist in plants (see 2.2.5.3) as well as in engineered devices. From the point of view of energy consumption, the most interesting feature of bi-stable structures is their ability to retain a shape without the need of a continuous actuating force [165]. Only the alternation from one shape to another requires an energy supply. Those structures combine an energy storage strategy with a flexible shell or beam (control of stiffness) and a material heterogeneity along the thickness of the structure. In steel tapes, residual fabrication stresses can determine the geometry in the bi-stable behavior [166]. Two positions with opposite sign curvatures can accommodate those stresses by membrane effect. In [165], the small output displacement of a shape memory alloy actuator heated by an electrical current is amplified by the snap-through of a bi-stable unsymmetrical carbon-epoxy laminate plate. With a SMA wire fixed by supports at a distance from the laminate in order to apply a moment to the structure, various fiber orientations were tested, and experimental and predicted values of strain and temperature before and after the snap-through were compared.

In [167] (Figure 21), this snap-through mechanism is also coupled with a compliant lever in order to reach a total KAR of 90, for the actuation of control fins in projectiles. We note that each amplification mechanism can perform different sub-functions: the snap-through mechanism guarantees the accuracy of the two equilibrium positions and the blocking force, while the lever-arm simply supplies sufficient trigger force and displacement to actuate the thin plate.

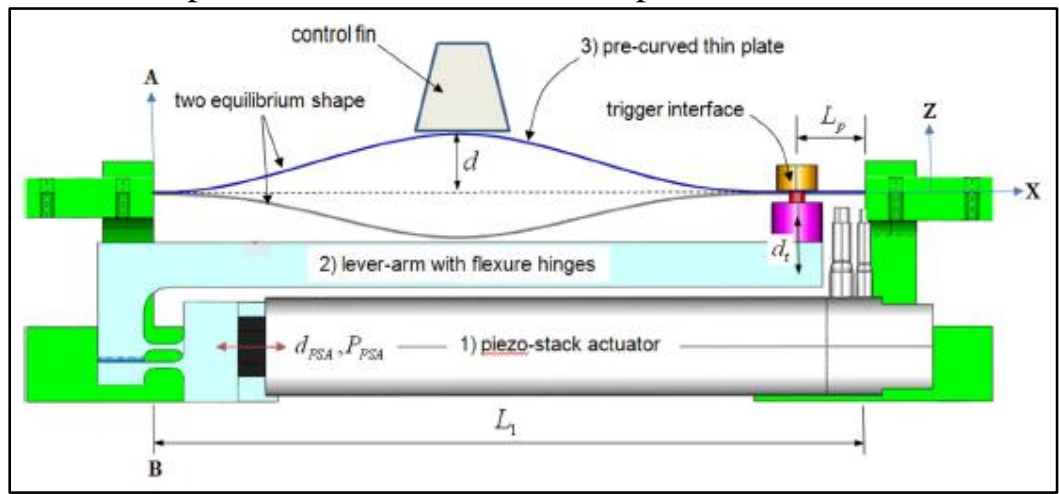

Figure 21: Snap-through fin, reproduced from [160] 


\subsubsection{Anisotropy and swelling}

A third coupling of movement strategies is the combination of an inflatable structure with material anisotropy. In [168] an inflatable corridor is proposed as an adaptive building with changing volume and changing envelope cross-section. A pattern of inflatable cells is embedded with steel cable circulating across the thickness of the wall. By controlling the inflation and the cable tension, the structure can be easily deformed and shaped into freeform surfaces, including doubly curved geometries. A combination of the anisotropic swelling strategies and the bilayer strategy seen in plants ([6]) can be seen as an engineered structure combining quarter cut veneer of maple wood with a glass fiber reinforced plastic layer in [169], and particularly in the Hygroskin pavilion (Achim Menges, 2013, Orléans, France) (Figure 22). This meteorosensitive skin is inspired by the natural behavior of pine cones under humidity variations and combines the hygroscopic and mechanical properties of wood inside a semi-synthetic adaptive bilayer material. Wood is a natural composite material. Its anisotropy is mainly due to the orientation of the wood cells along the stem axis of the tree. The differential absorption or diffusion on the internal and external faces of the wood induces different levels of humidity across the bilayer material. The differential expansion generates swelling and thus curvature. The material responds by dissipating the stress through an elastic deformation. The swelling most commonly observed is perpendicular to the fibers direction. This hygroscopic bilayer effect is used on the 1100 apertures making up the 28 opening modules. The polygonal apertures are closed at a high level of relative humidity around $85 \%$ and fully opened by curvature at the lowest level around $45 \%$, taking into account the climatology parameters of the installation site.

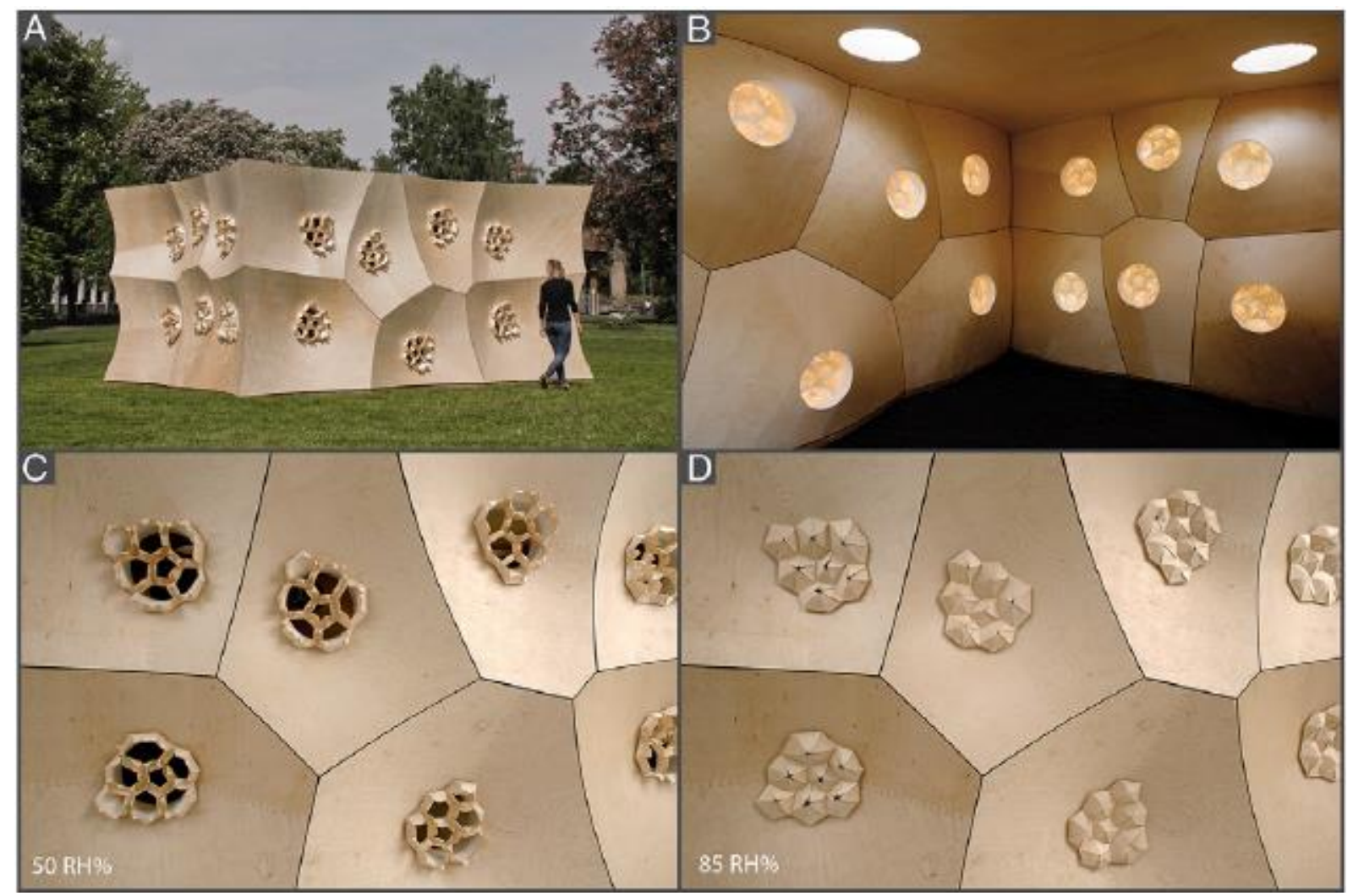

Figure 22: Hygroskin installation - Achim Menges, 2013, Orléans - France. Reproduced from [169]with permission from Elsevier

\subsubsection{Geometry-enhanced control of stiffness}

Flexible structures can combine geometrical complexity and stiffness strategies by curved folding. Folded structures occur frequently in plants: in rigid folding, the surfaces between creases do not deform - which makes it a storage strategy rather than a movement strategy -, but in curved crease folding, the surface curvatures and the fold line curvature are mechanically coupled, offering an variety of shapes [170]. In [171] the potential of curved folds in flexible, bio-inspired structures has been studied. The 
design of a specific geometry and relevant creases (Figure 23), coupled with flexible surfaces made of FRP, leads to a hingeless adaptive structure that has potential as a solar shade. In analogy to this system, a small strain in the middle rib of the Aldrovanda vesiculosa results in a large movement to capture a prey. The same mechanical transmission can be used to realize important solar shadowing on free-form building envelopes, which could lead to a new paradigm: flexible adaptive instead of rigid-body hinged adaptive building facades.

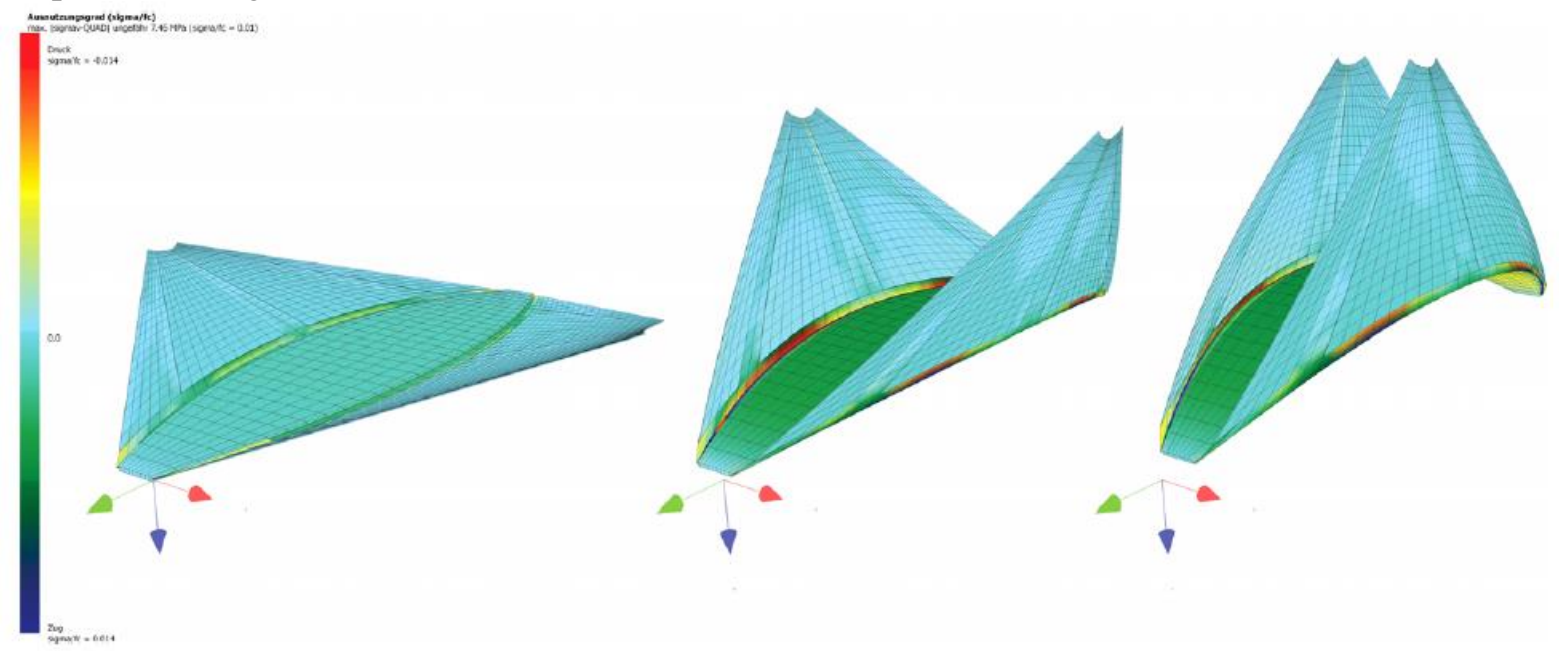

Figure 23: Hingeless shading device, kinematic simulation, reproduced from [171]with permission from Elsevier

As can be seen in [172], some key geometrical parameters like the crease orientation and crease radius leading to bi-stable or mono-stable curved crease structures, can be identified. In this case, the displacement amplification happens at the moment of snap-through and can transform a small-stroke movement into a bigger output displacement. However this system relies on previously accumulated energy. Curved folding, besides geometry and stiffness strategies, is closely linked to energy storage because it enables to store bending energy inside the structure in form of surface stresses. Curved crease folded structures use this energy storage in order to elastically return to a reference position, once the actuation stimulation ends.

\subsubsection{Energy storage and fluid compressibility}

This combination is not observed very often in engineering, but some research has been made on multistable structures with pressure-dependent shapes. In [173], Li \& Wang propose a kinetic system based on Miura-Ori origami patterns, where the number of stable shapes can be set by adjusting the internal pressure in fluidic cells. 


\section{Discussion and Conclusions}

The complete study of plant movements involve a breadth of biophysical and biochemistry sciences. In plant mechanics, kinematics emanate from the entanglement of material and structure at the tissue scale. From the hierarchical assemblage of cells stems an extremely evolved active, living material capable of sensing, actuating and carrying loads.

The mechanism implemented in plants structures have been classified in five distinct categories: differential expansion through controlled, localized swelling and shrinking of active cells, differential expansion of a highly anisotropy layered body under re-hydration, fast release of stored elastic energy, rigid-bar and beam-buckling mechanisms and finally the coupling of geometry and shell mechanics. Plants implement purely mechanical strategies to amplify the movements. First and foremost, differential expansion within a layered-solid is the most common strategy for movements of plants.

In active movements, the organ called pulvinus performs differential expansion based on turgor pressure variations. In its most advanced form the pulvinus achieves spherical, two degree-of-freedom, movements. In simpler variations, pulvinus movements are planar, one degree-of-freedom. In passive movements of fruits and seeds, anisotropic expansion of dry cells caused by external environment parameters such as diurnal cycle hygrometric variations generates large plant displacements. Mechanical displacement-amplification strategies such as lever action and torsional buckling enable flower passive movements. Pollinators actuate the mechanism by their weight or attempt to collect nectar. The actuation in passive movements therefore comes at no metabolic cost for the plant. In functions requiring speed, such as predatory nutrition, pollination by deception or release of seeds, elastic instabilities and geometric effects allow the fast release of energy powering the movement. The compliance of the material allows the large variations of shape between the different states of the mechanism.

The mechanics of carnivorous plants have been extensively studied and their movements documented. However, many other plant movements are still unexplored. For example, only a limited number of fast flower movements have been mechanically characterized. The Australian genus Pterostylis, known for its hinged column/labellum, has an estimated 400 species alone [101] none of which have been studied for their mechanics. Countless other genera with hinged columns/labella have been reported [174-179]. The mechanical characterization of those movements certainly constitutes a large source of unexplored information about plant movements.

In the context of this study actuators for manmade mechanisms are reviewed and discussed. Those mechanisms rely on the material properties and geometry of their constituents for actuation. Motorless, hingeless and wheel-less actuation is based on material deformations (expansion, incompressibility...) resulting in small amplitude displacements. These mechanisms therefore frequently resort to a movement amplification, and parallels can be drawn with plant amplification strategies. For manufacturing reasons, these deformation-based actuation patterns are widespread at micrometer scale, which is why various examples are drawn from the field of micro-electro mechanical structures. One can distinguish four displacement amplification strategies: a geometrical strategy, controlling the material properties like stiffness, anisotropy or thermal expansion coefficients, the swelling and shrinkage, and the storage of energy. These strategies can be found in plant movements. Plants and manmade mechanisms often implement various displacement strategies at the same time, and each one can have its own function for the output movement. The combination of amplification strategies can also allow other mechanical features such as for example the stability of some zero-energy positions. These couplings of strategies have been assembled into table 1. Some kinematic amplification ratios (KAR) have been cited in this paper, although a lack of quantitative data has been remarked in the literature, especially in the biological field: either the papers studied by the authors focused on other indicators describing the performance of the deployable elements, or the kinematic data was not available at all. Nevertheless, the efficiency of the bilayer amplification can be highlighted in relation to other manmade mechanisms: it reaches a KAR of 140, an order of magnitude higher than the other listed strategies. This clearly provides a parallel between engineered moving devices and moving plants: the bilayer effect caused by the differential expansion of cells or by the cell anisotropy in hygroscopic tissues is also the most widespread amplification mechanism in plants, probably because it is the most efficient. 


\begin{tabular}{|c|c|c|c|c|}
\hline Couplings of strategies & $\begin{array}{c}\text { Variation of } \\
\text { material } \\
\text { properties } \\
\end{array}$ & $\begin{array}{l}\text { Geometrical } \\
\text { strategies }\end{array}$ & Energy storage & $\begin{array}{l}\text { Fluid incompressibility / } \\
\text { Swelling and Shrinkage }\end{array}$ \\
\hline $\begin{array}{l}\text { Variation of material } \\
\text { properties }\end{array}$ & & $\begin{array}{c}\text { Aldrovanda } \\
\text { vesiculosa [20]: } \\
\text { Turgor bilayer } \\
\text { action coupled with } \\
\text { double curved shell } \\
\text { bending }\end{array}$ & $\begin{array}{l}\text { Explosive seed } \\
\text { dispersal in } \\
\text { Impatiens [94]: } \\
\text { material } \\
\text { incompressibility } \\
\text { and prestressed } \\
\text { beams } \\
\end{array}$ & $\begin{array}{l}\text { Fruits and seeds detached } \\
\text { from the vascular system: } \\
\text { increase of material } \\
\text { volume by hygroscopic } \\
\text { material directed by } \\
\text { strong anisotropy and } \\
\text { geometry effects }[6,77]\end{array}$ \\
\hline Geometrical strategies & $\begin{array}{l}\text { Flectofin [107]: } \\
\text { variation of the } \\
\text { composite } \\
\text { properties and } \\
\text { amplification } \\
\text { through shape } \\
\text { changes. }\end{array}$ & & $\begin{array}{c}\text { Dionaea } \\
\text { muscipula [20]: } \\
\text { Elastic } \\
\text { instabilities and } \\
\text { snap-through } \\
\text { mechanisms }\end{array}$ & $\begin{array}{l}\text { Fast movement of } \\
\text { Stylidium [120]: } \\
\text { Geometric effect of } \\
\text { progressive reversal of } \\
\text { transversal curvature in a } \\
\text { longitudinally curved } \\
\text { beam }\end{array}$ \\
\hline Energy storage & $\begin{array}{l}\text { Bistable steel } \\
\text { tape }[166]\end{array}$ & $\begin{array}{c}\text { Snap-through } \\
\text { mechanism [165]: } \\
\text { amplification } \\
\text { through shape } \\
\text { changes \& energy } \\
\text { storage }\end{array}$ & & $\begin{array}{l}\text { Pulvinus [68]: actuator } \\
\text { implementing bilayer } \\
\text { effect for two degrees of } \\
\text { freedom }\end{array}$ \\
\hline $\begin{array}{l}\text { Fluid incompressibility / } \\
\text { Swelling and Shrinkage }\end{array}$ & $\begin{array}{l}\text { Hygroscopic } \\
\text { pavilion [169]: } \\
\text { bilayer } \\
\text { mechanism \& } \\
\text { hygroscopic } \\
\text { swelling }\end{array}$ & $\begin{array}{l}\text { Array of inflatable } \\
\text { cells connected by } \\
\text { valves [148] }\end{array}$ & $\begin{array}{c}\text { Fluidic origami } \\
\qquad[173]\end{array}$ & \\
\hline
\end{tabular}

Table 1 Plant and engineering mechanisms classified with the strategies identified in section 3.2

The plant's microscale mechanical properties (mainly a stiff cell wall and the turgor pressure) and the entanglement of appropriate structural organizations at each scale make of plant tissues a genuine "smart material". They account for a variety of advanced structural features, some of them being usually avoided in engineering. Mechanical couplings like torsional buckling, and elastic instabilities like the snap-through phenomenon, testify to the great diversity of mechanisms that can be encountered in the plant's world. Their movements come with different speeds, kinematics, functions (e.g. sun-tracking, growth, reproduction, predation), and can be passive or active with numerous different triggers.

Most of the mechanical devices presented in this research are not directly bio-inspired, but many parallels have been drawn with plant movements. The systems studied here are based on multifunctionality and an optimized material hierarchy: they work with what may be called "deformationbased" actuation patterns. These enable precise, reliable, repeatable and low-energy movements. Even though there is still a lot to understand from the mechanics of plant movements, inspiration from the identified plant strategies combined with new manufacturing techniques, powerful modelling tools and advances in materials science can lead to promising applications in industrial fields as different as microscale medicine and construction.

\section{Acknowledgement}

This material is based upon work supported by the National Science Foundation under Grant No 1538330 and by the Andlinger Center Energy and the Environment at Princeton University. In addition, this work has been partially funded by ANRT under CIFRE grant No 2015/0495 and by Ingérop Group. 
1. Vincent, J.F., Adaptive Structures-Some Biological Paradigms. Adaptive Structures: Engineering Applications, 2008: p. 261-285.

2. Thill, C., et al., Morphing skins. The Aeronautical Journal, 2008. 112(1129): p. 117-139.

3. Wagg, D., et al., Adaptive structures: engineering applications. 2008: John Wiley \& Sons.

4. Dumais, J. and Y. Forterre, "Vegetable Dynamicks": the role of water in plant movements. Annual Review of Fluid Mechanics, 2012. 44: p. 453-478.

5. Forterre, Y., Slow, fast and furious: understanding the physics of plant movements. Journal of experimental botany, 2013: p. ert230.

6. Stahlberg, R., The phytomimetic potential of three types of hydration motors that drive nastic plant movements. Mechanics of Materials, 2009. 41(10): p. 1162-1171.

7. Burgert, I. and P. Fratzl, Actuation systems in plants as prototypes for bioinspired devices. Philosophical Transactions of the Royal Society of London A: Mathematical, Physical and Engineering Sciences, 2009. 367(1893): p. 1541-1557.

8. Burgert, I. and T. Keplinger, Plant micro-and nanomechanics: experimental techniques for plant cell-wall analysis. Journal of experimental botany, 2013: p. ert255.

9. Burgert, I. and P. Fratzl, Plants control the properties and actuation of their organs through the orientation of cellulose fibrils in their cell walls. Integrative and comparative biology, 2009. 49(1): p. 69-79.

10. Speck, T. and I. Burgert, Plant stems: functional design and mechanics. Annual Review of Materials Research, 2011. 41: p. 169-193.

11. Martone, P.T., et al., Mechanics without muscle: biomechanical inspiration from the plant world. Integrative and Comparative Biology, 2010. 50(5): p. 888-907.

12. Niklas, K.J., Plant biomechanics: an engineering approach to plant form and function. 1992: University of Chicago press.

13. Barbarino, S., et al., A review of morphing aircraft. Journal of Intelligent Material Systems and Structures, $2011.22(9)$ : p. 823-877.

14. Fiorito, F., et al., Shape morphing solar shadings: A review. Renewable and Sustainable Energy Reviews, 2016. 55: p. 863-884.

15. Ouyang, P., et al., Micro-motion devices technology: The state of arts review. The International Journal of Advanced Manufacturing Technology, 2008. 38(5-6): p. 463-478.

16. Lachenal, X., S. Daynes, and P.M. Weaver, Review of morphing concepts and materials for wind turbine blade applications. Wind Energy, 2013. 16(2): p. 283-307.

17. Barlas, T.K. and G. Van Kuik, Review of state of the art in smart rotor control research for wind turbines. Progress in Aerospace Sciences, 2010. 46(1): p. 1-27.

18. Daynes, S. and P.M. Weaver, Review of shape-morphing automobile structures: concepts and outlook. Proceedings of the Institution of Mechanical Engineers, Part D: Journal of Automobile Engineering, 2013. 227(11): p. 1603-1622.

19. Greco, F. and V. Mattoli, Introduction to Active Smart Materials for Biomedical Applications, in Piezoelectric Nanomaterials for Biomedical Applications, G. Ciofani and A. Menciassi, Editors. 2012, Springer Berlin Heidelberg: Berlin, Heidelberg. p. 1-27.

20. Poppinga, S. and M. Joyeux, Different mechanics of snap-trapping in the two closely related carnivorous plants Dionaea muscipula and Aldrovanda vesiculosa. Physical Review E, 2011. 84(4): p. 041928.

21. Dawson, C., J.F. Vincent, and A.-M. Rocca, How pine cones open. Nature, 1997. 390(6661): p. 668-668.

22. Kanthal, A., Thermostatic Bimetal Handbook. 1996, KANTHAL.

23. Patek, S., et al., Linkage mechanics and power amplification of the mantis shrimp's strike. Journal of Experimental Biology, 2007. 210(20): p. 3677-3688.

24. Currey, J.D., The mechanical adaptations of bones. 2014: Princeton University Press.

25. Preston, R.D., The physical biology of plant cell walls. 1974: London.: Chapman \& Hall.

26. Baskin, T.I., Anisotropic expansion of the plant cell wall. Annu. Rev. Cell Dev. Biol., 2005. 21: p. $203-222$.

27. Taiz, L. and E. Zeiger, Plant Physiology. Sunderland, MA. 2002, Sinauer Associates, Inc.

28. Green, P.B., Mechanism for plant cellular morphogenesis. Science, 1962. 138(3548): p. 1404-1405.

29. Van der Sman, R., Hyperelastic models for hydration of cellular tissue. Soft matter, 2015. 11(38): p. 7579-7591.

30. Baskin, T.I., et al., Disorganization of cortical microtubules stimulates tangential expansion and reduces the uniformity of cellulose microfibril alignment among cells in the root of Arabidopsis. Plant Physiology, 2004. 135(4): p. 2279-2290.

31. Dumais, J., S.R. Long, and S.L. Shaw, The mechanics of surface expansion anisotropy in Medicago truncatula root hairs. Plant physiology, 2004. 136(2): p. 3266-3275.

32. Gibson, L.J., The hierarchical structure and mechanics of plant materials. Journal of the Royal Society Interface, $2012:$ p. rsif20120341.

33. Warner, M., B. Thiel, and A. Donald, The elasticity and failure of fluid-filled cellular solids: theory and experiment. Proceedings of the National Academy of Sciences, 2000. 97(4): p. 1370-1375.

34. Probine, M. and R. Preston, Cell growth and the structure and mechanical properties of the wall in internodal cells of Nitella opaca: II. mechanical properties of the walls. Journal of Experimental Botany, 1962. 13(1): p. 111-127.

35. Spatz, H., L. Kohler, and K. Niklas, Mechanical behaviour of plant tissues: composite materials or structures? Journal of Experimental Biology, 1999. 202(23): p. 3269-3272.

36. Kroeger, J.H., R. Zerzour, and A. Geitmann, Regulator or driving force? The role of turgor pressure in oscillatory plant cell growth. PloS one, 2011. 6(4): p. e18549.

37. Zhao, L., et al., Elastic properties of the cell wall of Aspergillus nidulans studied with atomic force microscopy. Biotechnology progress, 2005. 21(1): p. 292-299.

38. Wang, C., L. Wang, and C. Thomas, Modelling the mechanical properties of single suspension - cultured tomato cells. Annals of Botany, 2004. 93(4): p. 443-453.

39. Lakkad, S. and J. Patel, Mechanical properties of bamboo, a natural composite. Fibre Science and Technology, 1981. 14(4): p. 319-322.

40. Green, D.W., J.E. Winandy, and D.E. Kretschmann, Mechanical properties of wood. 1999.

41. Gibson, L.J., M.F. Ashby, and B.A. Harley, Cellular Materials in Nature and Medicine. 2010: Cambridge University Press.

42. Mihai, L.A., K. Alayyash, and A. Goriely. Paws, pads and plants: the enhanced elasticity of cell-filled load-bearing structures. in Proc. R. Soc. A. 2015. The Royal Society.

43. Niklas, K.J., Mechanical behavior of plant tissues as inferred from the theory of pressurized cellular solids. American Journal of Botany, 1989: p. 929-937.

44. Nobel, P.S., Physicochemical and environmental plant physiology. 1999: Academic press.

45. Philip, J., Propagation of Turgor and Other Properties Through Cell Aggregations. Plant Physiology, $1958.33(4)$ : p. 271.

46. Koch, G.W., et al., The limits to tree height. Nature, 2004. 428(6985): p. 851-854.

47. Knippers, J. and T. Speck, Design and construction principles in nature and architecture. Bioinspiration \& biomimetics, 2012. 7(1): p. 015002.

48. Elices, M., Structural biological materials: design and structure-property relationships. Vol. 4. 2000: Elsevier.

49. Dunlop, J.W. and P. Fratzl, Biological composites. Annual Review of Materials Research, 2010. 40: p. 1-24. 
50. Vogel, S., Cats' paws and catapults: Mechanical worlds of nature and people. 2000: WW Norton \& Company.

51. Aizenberg, J., et al., Skeleton of Euplectella sp.: structural hierarchy from the nanoscale to the macroscale. Science, 2005. 309(5732): p. $275-278$.

52. Keckes, J., et al., Cell-wall recovery after irreversible deformation of wood. Nature materials, 2003. 2(12): p. 810-813.

53. Fantner, G.E., et al., Sacrificial bonds and hidden length: unraveling molecular mesostructures in tough materials. Biophysical Journal, 2006. 90(4): p. 1411-1418.

54. Malvern, L.E., Introduction to the Mechanics of a Continuous Medium. 1969.

55. Nishizaki, Y., Effects of anoxia and red light on changes induced by blue light in the membrane potential of pulvinar motor cells and leaf movement in Phaseolus vulgaris L. Plant and cell physiology, 1990. 31(5): p. 591-596.

56. Rodrigues, T. and S. Machado, The Pulvinus Endodermal Cells and their Relation to Leaf Movement in Legumes of the Brazilian Cerrado*. Plant Biology, 2007. 9(4): p. 469-477.

57. Stanton, M.L. and C. Galen, Blue light controls solar tracking by flowers of an alpine plant. Plant, Cell \& Environment, 1993. 16(8): p. 983-989.

58. Christie, J.M. and A.S. Murphy, Shoot phototropism in higher plants: new light through old concepts. American Journal of Botany, 2013. 100(1): p. 35-46.

59. Schwartz, A. and D. Koller, Diurnal phototropism in solar tracking leaves of Lavatera cretica. Plant physiology, 1986. 80(3): p. 778781.

60. Werker, E. and D. Koller, Structural specialization of the site of response to vectorial photo-excitation in the solar-tracking leaf of Lavatera cretica. American journal of botany, 1987: p. 1339-1349.

61. Schwartz, A. and D. Koller, Phototropic response to vectorial light in leaves of Lavatera cretica L. Plant physiology, 1978. 61(6): p. 924-928.

62. Dicker, M., et al., Biomimetic photo-actuation: sensing, control and actuation in sun-tracking plants. Bioinspiration \& biomimetics, 2014. 9(3): p. 036015.

63. Fleurat-Lessard, P. and R.L. Satter, Relationships between structure and motility ofAlbizzia motor organs: Changes in ultrastructure of cortical cells during dark-induced closure. Protoplasma, 1985. 128(1): p. 72-79.

64. Mayer, W.-E., et al., Mechanics of circadian pulvini movements in Phaseolus coccineus L. Planta, 1985. 163(3): p. 381-390.

65. Hill, B.S. and G.P. Findlay, The power of movement in plants: the role of osmotic machines. Quarterly reviews of biophysics, 1981. 14(02): p. 173-222.

66. Volkov, A.G., et al., Mimosa pudica: Electrical and mechanical stimulation of plant movements. Plant, cell \& environment, 2010. 33(2): p. 163-173.

67. Skotheim, J.M. and L. Mahadevan, Physical limits and design principles for plant and fungal movements. Science, 2005. 308(5726): p. 1308-1310.

68. Song, K., E. Yeom, and S.J. Lee, Real-time imaging of pulvinus bending in Mimosa pudica. Scientific reports, 2014. 4

69. Moran, N., Rhythmic leaf movements: physiological and molecular aspects, in Rhythms in Plants. 2015, Springer. p. 57-95.

70. Roblin, G., Mimosa pudica: a model for the study of the excitability in plants. Biological Reviews, 1979. 54(2): p. 135-153.

71. Fromm, J. and W. Eschrich, Transport processes in stimulated and non-stimulated leaves of Mimosa pudica. Trees, 1988. 2(1): p. 7-17.

72. Moshelion, M., et al., Plasma Membrane Aquaporins in the Motor Cells of Samanea saman Diurnal and Circadian Regulation. The Plant Cell, 2002. 14(3): p. 727-739.

73. Piéron, H., Du rôle de la mémoire dans les rythmes biologiques. Revue Philosophique de la France et de l'Étranger, 1909. 68: p. 17-48.

74. Miah, M.I. and A. Johnsson, Effects of light stimulion Desmodium Gyrans lateral leaflet movement Rhythms. 2004.

75. Dai, A., et al., Diurnal variation in water vapor over North America and its implications for sampling errors in radiosonde humidity. Journal of Geophysical Research: Atmospheres, 2002. 107(D10).

76. Couturier, E., et al., Folding of an opened spherical shell. Soft Matter, 2013. 9(34): p. 8359-8367.

77. Katifori, E., et al., Foldable structures and the natural design of pollen grains. Proceedings of the National Academy of Sciences, 2010. 107(17): p. 7635-7639.

78. Couturier, E. Folded isometric deformations and banana-shaped seedpod. in Proc. R. Soc. A. 2016. The Royal Society.

79. Bar-On, B., et al., Structural origins of morphing in plant tissues. Applied Physics Letters, 2014. 105(3): p. 033703.

80. Heslop-Harrison, J., An interpretation of the hydrodynamics of pollen. American Journal of Botany, $1979:$ p. $737-743$.

81. Heslop-Harrison, J., Pollen walls as adaptive systems. Annals of the Missouri Botanical Garden, 1979. 66(4): p. 813-829.

82. Volkova, O.A., E.E. Severova, and S.V. Polevova, Structural basis of harmomegathy: evidence from Boraginaceae pollen. Plant systematics and evolution, 2013. 299(9): p. 1769-1779.

83. Halbritter, H. and M. Hesse, Principal modes of infoldings in tricolp (or) ate Angiosperm pollen. Grana, 2004. 43(1): p. 1-14.

84. Landau, L.D. and E. Lifshitz, Theory of Elasticity, vol. 7. Course of Theoretical Physics, 1986. 3: p. 109.

85. Armon, S., et al., Geometry and mechanics in the opening of chiral seed pods. Science, 2011. 333(6050): p. 1726-1730.

86. Shtein, I., R. Elbaum, and B. Bar-On, The Hygroscopic Opening of Sesame Fruits Is Induced by a Functionally Graded Pericarp Architecture. Frontiers in Plant Science, 2016. 7.

87. Forterre, Y. and J. Dumais, Generating helices in nature. science, 2011. 333(6050): p. 1715-1716.

88. Elbaum, R., et al., The role of wheat awns in the seed dispersal unit. Science, 2007. 316(5826): p. 884-886.

89. Le Duigou, A. and M. Castro, Evaluation of force generation mechanisms in natural, passive hydraulic actuators. Scientific reports, 2016. 6 .

90. Stamp, N.E., Self-burial behaviour of Erodium cicutarium seeds. The Journal of Ecology, 1984: p. 611-620.

91. Stamp, N.E., Efficacy of explosive vs. hygroscopic seed dispersal by an annual grassland species. American Journal of Botany, 1989: p. $555-561$.

92. Reyssat, E. and L. Mahadevan, Hygromorphs: from pine cones to biomimetic bilayers. Journal of the Royal Society Interface, 2009: p. rsif20090184.

93. Vogel, S., Glimpses of creatures in their physical worlds. 2009: Princeton University Press.

94. Deegan, R.D., Finessing the fracture energy barrier in ballistic seed dispersal. Proceedings of the National Academy of Sciences, 2012. 109(14): p. 5166-5169.

95. Hayashi, M., K.L. Feilich, and D.J. Ellerby, The mechanics of explosive seed dispersal in orange jewelweed (Impatiens capensis). Journal of experimental botany, 2009: p. erp070.

96. Hulme, P.E. and E.T. Bremner, Assessing the impact of Impatiens glandulifera on riparian habitats: partitioning diversity components following species removal. Journal of Applied Ecology, 2006. 43(1): p. 43-50.

97. Perrins, J., A. Fitter, and M. Williamson, Population biology and rates of invasion of three introduced Impatiens species in the British Isles. Journal of Biogeography, 1993: p. 33-44.

98. Beerling, D.J. and J.M. Perrins, Impatiens glandulifera Royle (Impatiens roylei Walp.). Journal of Ecology, 1993. 81(2): p. 367-382.

99. Meyer, H., Applications of Physics to Archery. arXiv preprint arXiv:1511.02250, 2015. 
100. Lunau, K., A new interpretation of flower guide colouration: absorption of ultraviolet light enhances colour saturation. Plant systematics and Evolution, 1992. 183(1-2): p. 51-65.

101. Phillips, R.D., et al., Caught in the act: pollination of sexually deceptive trap-flowers by fungus gnats in Pterostylis (Orchidaceae). Annals of botany, 2014. 113(4): p. 629-641.

102. Thomson, J.D. and R. Plowright, Pollen carryover, nectar rewards, and pollinator behavior with special reference to Diervilla lonicera. Oecologia, 1980. 46(1): p. 68-74

103. Thien, L.B. and B.G. Marcks, The floral biology of Arethusa bulbosa, Calopogon tuberosus, and Pogonia ophioglossoides (Orchidaceae). Canadian Journal of Botany, 1972. 50(11): p. 2319-2325.

104. Reith, M., et al., New insights into the functional morphology of the lever mechanism of Salvia pratensis (Lamiaceae). Annals of Botany, 2007. 100(2): p. 393-400.

105. Kronestedt, E. and B. Walles, Anatomy of the Strelitzia reginae flower (Strelitziaceae). Nordic Journal of Botany, 1986. 6(3): p. 307-320.

106. Meeuse, B. and S. Morris, Sex life of flowers. 1984: Facts on File.

107. Lienhard, J., et al., Flectofin: a hingeless flapping mechanism inspired by nature. Bioinspiration \& Biomimetics, $2011.6(4)$ : p. 045001.

108. Schleicher, S., Bio-inspired compliant mechanisms for architectural design: transferring bending and folding principles of plant leaves to flexible kinetic structures. 2015.

109. Lienhard, J., et al. Abstraction of plant movements for deployable structures in architecture. in Proceedings of the 6th Plant Biomechanics Conference. 2009.

110. Bauer, U., et al., With a flick of the lid: a novel trapping mechanism in Nepenthes gracilis pitcher plants. PloS one, 2012. 7(6): p. e38951.

111. Bauer, U., et al., Mechanism for rapid passive-dynamic prey capture in a pitcher plant. Proceedings of the National Academy of Sciences, 2015. 112(43): p. 13384-13389.

112. Adamec, L., Photosynthetic characteristics of the aquatic carnivorous plant Aldrovanda vesiculosa. Aquatic Botany, 1997. 59(3): p. 297-306.

113. Adamec, L., Rootless aquatic plant Aldrovanda vesiculosa: physiological polarity, mineral nutrition, and importance of carnivory. Biologia Plantarum, 2000. 43(1): p. 113-119.

114. Iijima, T. and T. Sibaoka, Action potential in the trap-lobes of Aldrovanda vesiculosa. Plant and cell physiology, 1981. 22(8): p. 15951601.

115. Sibaoka, T., Physiology of rapid movements in higher plants. Annual Review of Plant Physiology, 1969. 20(1): p. 165-184.

116. Ackerman, J.D., Mechanisms and evolution of food-deceptive pollination systems in orchids. Lindleyana, 1986. 1(2): p. 108-113.

117. Dafni, A., Mimicry and deception in pollination. Annual Review of Ecology and Systematics, 1984. 15: p. $259-278$.

118. Darwin, C., The various contrivances by which orchids are fertilised by insects. 1888: John Murrary.

119. Lehnebach, C.A., A.W. Robertson, and D. Hedderley, Pollination studies of four New Zealand terrestrial orchids and the implication for their conservation. New Zealand Journal of Botany, 2005. 43(2): p. 467-477.

120. Findlay, G. and N. Findlay, Anatomy and movement of the column in Stylidium. Functional Plant Biology, 1975. 2(4): p. 597-621.

121. Findlay, N. and G. Findlay, The structure of the column in Stylidium. Australian journal of botany, 1989. 37(1): p. 81-101.

122. Sharma, V.K., T.K. Bardal, and A. Johnsson, Light-dependent changes in the leaflet movement rhythm of the plant Desmodium gyrans. Zeitschrift für Naturforschung C, 2003. 58(1-2): p. 81-86.

123. Findlay, G., Generation of torque by the column of Stylidium. Functional Plant Biology, 1982. 9(3): p. 271-286.

124. Joyeux, M., O. Vincent, and P. Marmottant, Mechanical model of the ultrafast underwater trap of Utricularia. Physical Review E, 2011. 83(2): p. 021911.

125. Sydenham, P. and G. Findlay, The rapid movement of the bladder of Utricularia sp. Australian Journal of Biological Sciences, 1973. 26(5): p. 1115-1126.

126. Vincent, O., et al., Ultra-fast underwater suction traps. Proceedings of the Royal Society of London B: Biological Sciences, 2011. 278(1720): p. 2909-2914.

127. Darwin, C. and F. Darwin, Insectivorous plants. 1888: J. Murray.

128. Forterre, Y., et al., How the Venus flytrap snaps. Nature, 2005. 433(7024): p. 421-425.

129. Yang, R., et al., A mathematical model on the closing and opening mechanism for Venus flytrap. Plant signaling \& behavior, 2010. 5(8): p. 968-978.

130. Markin, V.S., A.G. Volkov, and E. Jovanov, Active movements in plants: mechanism of trap closure by Dionaea muscipula Ellis. Plant signaling \& behavior, 2008. 3(10): p. 778-783.

131. Volkov, A.G., et al., Kinetics and mechanism of Dionaea muscipula trap closing. Plant Physiology, 2008. 146(2): p. 694-702.

132. Volkov, A.G., et al., Venus flytrap biomechanics: Forces in the Dionaea muscipula trap. Journal of plant physiology, 2013. 170(1): p. 25-32.

133. Böhm, J., et al., The Venus Flytrap Dionaea muscipula Counts Prey-Induced Action Potentials to Induce Sodium Uptake. Current Biology, 2016

134. Timoshenko, S.P. and J.M. Gere, Theory of elastic stability. 2009: Courier Corporation.

135. Hodick, D. and A. Sievers, On the mechanism of trap closure of Venus flytrap (Dionaea muscipula Ellis). Planta, 1989. 179(1): p. 32-42.

136. Pons, J.L., Emerging actuator technologies: a micromechatronic approach. 2005: John Wiley \& Sons.

137. Jiang, J. and E. Mockensturm, A motion amplifier using an axially driven buckling beam: I. design and experiments. Nonlinear Dynamics, 2006. 43(4): p. 391-409.

138. Jack, W.J., Microelectromechanical systems (MEMS): fabrication, design and applications. Smart Materials and Structures, 2001. 10(6): p. 1115.

139. Zhang, D., Advanced Mechatronics and MEMS Devices. 2012: Springer New York.

140. Ashby, M.F., Materials Selection in Mechanical Design. 2004: Elsevier Science.

141. Chambers, E., Cyclopaedia: Or an Universal Dictionary of Arts and Sciences (etc.) -London, D. Midwinter 1741-1743. Vol. 1. 1741: D. Midwinter.

142. Prechtl, E.F. and S.R. Hall, Design of a high efficiency, large stroke, electromechanical actuator. Smart Materials and Structures, 1999. 8(1): p. 13.

143. Takatsuka, M. and H. Ohmori, Dynamic Structural Analysis of Deployment of Scissors Structure in Space. International Journal of Space Structures, 2013. 28(1): p. 1-13.

144. Korkmaz, K., Generation of a New Type of Architectural Umbrella. International Journal of Space Structures, $2005.20(1)$ : p. 35-41.

145. Lott, C.D., et al., Modeling the thermal behavior of a surface-micromachined linear-displacement thermomechanical microactuator. Sensors and Actuators A: Physical, 2002. 101(1-2): p. 239-250.

146. Masching, H. and K.-U. Bletzinger, Parameter free structural optimization applied to the shape optimization of smart structures. Finite Elements in Analysis and Design, 2016. 111: p. 33-45.

147. Ueda, J., T.W. Secord, and H.H. Asada, Large effective-strain piezoelectric actuators using nested cellular architecture with exponential strain amplification mechanisms. Mechatronics, IEEE/ASME Transactions on, 2010. 15(5): p. 770-782. 
148. Sinn, T., D. Hilbich, and M. Vasile, Inflatable shape changing colonies assembling versatile smart space structures. Acta Astronautica, 2014. 104(1): p. 45-60.

149. Charpentier, V., S. Adriaenssens, and O. Baverel, Large Displacements and the Stiffness of a Flexible Shell. International Journal of Space Structures, 2015. 30(3-4): p. 287-296.

150. Saavedra Flores, E.I., M.I. Friswell, and Y. Xia, Variable stiffness biological and bio-inspired materials. Journal of Intelligent Material Systems and Structures, 2013. 24(5): p. 529-540.

151. Juuti, J., et al., Mechanically amplified large displacement piezoelectric actuators. Sensors and Actuators A: Physical, 2005. 120(1): p. 225-231.

152. Lobontiu, N. and E. Garcia, Analytical model of displacement amplification and stiffness optimization for a class of flexure-based compliant mechanisms. Computers \& structures, 2003. 81(32): p. 2797-2810.

153. Feng, Y.-Y., et al., Fabrication of an electro-thermal micro-gripper with elliptical cross-sections using silver-nickel composite ink. Sensors and Actuators A: Physical, 2016. 245: p. 106-112.

154. Kim, D.H., Y.C. Park, and S. Park, Design and fabrication of twisting-type thermal actuation mechanism for micromirrors. Sensors and Actuators A: Physical, 2010. 159(1): p. 79-87.

155. Sung, D.K., “Bloom” Pavillion. 2011: Los Angeles.

156. SOMA, A., One Ocean Pavilion. 2012: Yeosu, South Korea.

157. Sunfolding. 2014; Available from: http://www.sunfolding.com/products/, accessed 2017-01-30.

158. Ninomiya, T., et al., MEMS-based hydraulic displacement amplification mechanism with completely encapsulated liquid. Sensors and Actuators A: Physical, 2011. 166(2): p. 277-282.

159. Gantes, C.J., Deployable structures: analysis and design. 2001: Wit Press.

160. Pellegrino, S., Deployable Structures. 2002: Springer Vienna.

161. Gantes, C.J. and E. Konitopoulou, Geometric design of arbitrarily curved bi-stable deployable arches with discrete joint size. International Journal of Solids and Structures, 2004. 41(20): p. 5517-5540.

162. Turcaud, S., et al., An excursion into the design space of biomimetic architectured biphasic actuators. International Journal of Materials Research, 2011. 102(6): p. 607-612.

163. Jeong, K.-U., et al., Three-dimensional actuators transformed from the programmed two-dimensional structures via bending, twisting and folding mechanisms. Journal of Materials Chemistry, 2011. 21(19): p. 6824-6830.

164. Pal, S. and H. Xie. Analysis and simulation of curved bimorph microactuators. in Microtech Conference and Expo (Nanotech 2010 , vol. 2), Anaheim, CA. 2010.

165. Dano, M.L. and M.W. Hyer, SMA-induced snap-through of unsymmetric fiber-reinforced composite laminates. International Journal of Solids and Structures, 2003. 40(22): p. 5949-5972.

166. Kebadze, E., S.D. Guest, and S. Pellegrino, Bistable prestressed shell structures. International Journal of Solids and Structures, 2004. 41(11-12): p. 2801-2820.

167. Kang, C.-G., J.-S. Lee, and J.-H. Han, Development of bi-stable and millimeter-scale displacement actuator using snap-through effect for reciprocating control fins. Aerospace Science and Technology, 2014. 32(1): p. 131-141.

168. Suma, A.B., F. van Herwijnen, and J.C.T. Voorthuis, 3D Adaptable Building Skin: Adaptive Space as a Guide through a Corridor. International Journal of Space Structures, 2007. 22(3): p. 169-177.

169. Reichert, S., A. Menges, and D. Correa, Meteorosensitive architecture: Biomimetic building skins based on materially embedded and hygroscopically enabled responsiveness. Computer-Aided Design, 2015. 60: p. 50-69.

170. Lebée, A. and A. Lebée, From Folds to Structures, a Review. International Journal of Space Structures, 2015. 30(2): p. 55-74.

171. Schleicher, S., et al., A methodology for transferring principles of plant movements to elastic systems in architecture. Computer-Aided Design, 2015. 60: p. 105-117.

172. Bende, N.P., et al., Geometrically controlled snapping transitions in shells with curved creases. Proceedings of the National Academy of Sciences, 2015. 112(36): p. 11175-11180.

173. Li, S. and K. Wang, Fluidic origami with embedded pressure dependent multi-stability: a plant inspired innovation. Journal of The Royal Society Interface, 2015. 12(111): p. 20150639.

174. Peakall, R., Responses of male Zaspilothynnus trilobatus Turner wasps to females and the sexually deceptive orchid it pollinates. Functional Ecology, 1990: p. 159-167.

175. Alcock, J., Interactions between the sexually deceptive orchid Spiculaea ciliata and its wasp pollinator Thynnoturneria sp.(Hymenoptera: Thynninae). Journal of Natural History, 2000. 34(4): p. 629-636.

176. Drummond, J., Remarks on the roots of some of the terrestrial Orchideae of Australia found in the neighbourhood of the Swan River. Gardener's Magazine, 1838. 14: p. 425-429.

177. Hopper, S.D. and A.P. Brown, Australia's wasp-pollinated flying duck orchids revised (Paracaleana: Orchidaceae). Australian Systematic Botany, 2006. 19(3): p. 211-244.

178. Davies, K.L. and M. Stpiczyńska, Labellar anatomy and secretion in Bulbophyllum Thouars (Orchidaceae: Bulbophyllinae) sect. Racemosae Benth. \& Hook. f. Annals of botany, 2014: p. mcu153.

179. Jones, D., A Complete Guide to Native Orchids of Australia, Including the Island Territories.,(New Holland Publishers: Sydney.). 2006. 